FERNANDO DE SÁ SILVA

Investigação da Capacidade Imunomoduladora de Células-Tronco Imaturas de Polpa Dentária humana

Tese apresentada ao Programa de PósGraduação Interunidades em Biotecnologia USP/ Instituto Butantan/ IPT, para obtenção do Título de Doutor em Biotecnologia. 
FERNANDO DE SÁ SILVA

\section{Investigação da Capacidade Imunomoduladora de Células-Tronco Imaturas de Polpa Dentária humana}

Tese apresentada ao Programa de Pós-Graduação Interunidades em Biotecnologia USP/ Instituto Butantan/ IPT, para obtenção do Título de Doutor em Biotecnologia.

Área de Concentração: Biotecnologia

Orientador: Dr. Carlos Magno da Costa Maranduba

Versão original 
DADOS DE CATALOGAÇÃO NA PUBLICAÇÃo (CIP)

Serviço de Biblioteca e Informaçăo Biomédica do

Instituto de Ciências Biomédicas da Universidade de Såo Paulo

(1) reproduçăo total

Silva, Fernando de Sá.

Investigaçăo da capacidade imunomoduladora de células-tronco

imaturas de polpa dentária / Fernando de Sá Silva. -- Săo Paulo, 2012.

Orientador: Prof. Dr. Carlos Magno da Costa Maranduba.

Tese (Doutorado) - Universidade de São Paulo. Instituto de Ciências Biomédicas. Programa de Pós-Graduaçăo Interunidades em Biotecnologia USP/IPT/Instituto Butantan. Área de concentraçăo: Biotecnologia. Linha de pesquisa: Células-tronco.

Versão do titulo para o inglês: Investigation of immunomodulatory capacity of human immature dental pulp stem cells.

$\begin{array}{lll}\text { 1. Celulas-tronco 2. Células dendriticas 3. Diferenciaçăo } & \end{array}$

4. Imunomodulaçăo 5. Linfócitos T I. Maranduba, Prof. Dr. Carlos Magno da Costa II. Universidade de Săo Paulo. Instituto de Ciências Biomédicas. Programa de Pós-Graduação Interunidades em

Biotecnologia USP/IPT/Instituto Butantan III. Título. 
Candidato(a): $\quad$ Fernando de Sá Silva.

Título da Tese: Investigaçăo da capacidade imunomoduladora de célulastronco imaturas de polpa dentária.

Orientador(a): $\quad$ Prof. Dr. Carlos Magno da Costa Maranduba.

A Comissăo Julgadora dos trabalhos de Defesa da Tese de Doutorado, em sessåo pública realizada a . considerou

( ) Aprovado(a) .. 


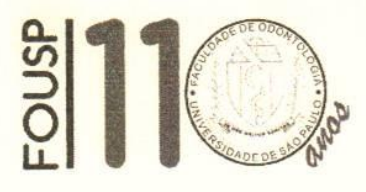

\author{
UNIVERSIDADE DE SÃO PAULO \\ FACULDADE DE ODONTOLOGIA \\ COMITÉ de ÉTICA EM PESQUISA
}

\author{
PARECER DE APROVAÇÃO \\ FR 407109 \\ Protocolo 129/10
}

Com base em parecer de relator, o Comitê de Ética em Pesquisa APROVOU o protocolo de pesquisa "Investigação da capacidade Imunomoduladora de células tronco imaturas de polpa dentária humana", de responsabilidade do(a) Pesquisador(a) Fernando de Sá Silva sob orientação do(a) Prof.(a) Dr.(a) Marcia Martins Marques.

Tendo em vista a legislação vigente, devem ser encaminhados a este Comitê relatórios anuais referentes ao andamento da pesquisa e ao término cópia do trabalho em "cd". Qualquer emenda do projeto original deve ser apresentada a este CEP para apreciação, de forma clara e sucinta, identificando a parte do a ser modificada e suas justificativas.

São Paulo, 19 de abril de 2011.

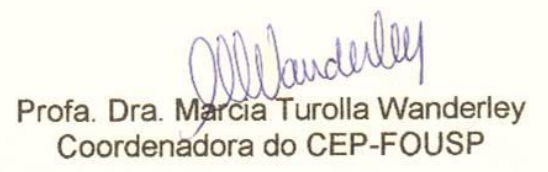

Av. Prof. Lineu Prestes, 2227 - Cidade Universitária "Armando de Salles Oliveira". São Paulo - SP - CEP 05508-900 -Tel. (0XX11) 3091-7960 


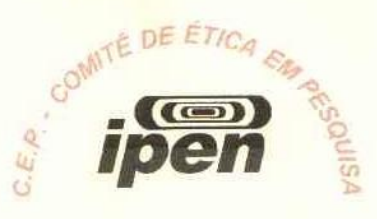

Parecer - Projeto $N^{\circ} 81 / 11$ - CEUA-IPEN/SP

Com base nos pareceres apresentados pelos relatores, 0 protocolo de pesquisa "INVESTIGAÇÃO DA CAPACIDADE IMUNOMODULADORA DE CÉLULAS TRONCO IMATURAS DE POLPA DENTÁRIA HUMANA. PROJETO DE DOUTORADO" de responsabilidade dos pesquisadores DR. CARLOS MAGNO DA COSTA MARANDUBA e CIBELE NUNES PERONI foi considerado APROVADO.

Tendo em vista a legislação vigente, devem ser encaminhados, a este Comitê, relatórios anuais (parciais ou finais, dependendo da duração do projeto) referentes ao andamento da pesquisa. Após o término da pesquisa, uma cópia do trabalho deve ser encaminhada a este CEUA.

São Paulo, 04 de maio de 2011

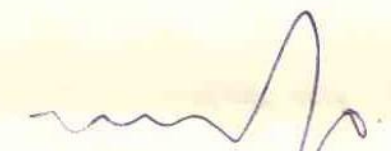

Profa. Dra. Nanci do Nascimento

Coordenadora do CEUA-IPEN

IPEN-CNEN/SP
COMITE DE ETICA EM PESQUISA ANIMAL

Av Prof Lineu Prestes 2242 - Cidade Universitária - CEP $05508-000$ - Săo Paulo - SP

Telefone: (011) 3133-9698- Fax (011) 3133-9709

E-mail: nnascime@ipen br 
Aos meus pais, pelo amor e dedicação incondicional em todos os momentos da minha vida, e pelo exemplo de vida.

Aos meus queridos irmãos, amigos de sempre e pra sempre! Pelo carinho, amizade incondicional, apoio, torcida, e por acreditarem neste sonho!

A minha amada namorada Tatiane, minha maior conquista,

pelo seu incentivo, amor, compreensão e cumplicidade em todos os momentos da nossa vida. 


\section{AGRADECIMENTOS}

Agradeço em especial ao Dr. Carlos Magno da Costa Maranduba, pela oportunidade, orientação, confiança e amizade tão importantes para a minha formação profissional e humana,.

À Dra. Márcia Martins Marques, por me receber em seu laboratório, pela amizade e incentivo.

Ao Dr. Osvaldo Augusto Brazil Esteves Sant'anna, pela atenção, pela amizade, incentivo e, principalmente, pelos conselhos.

Ao Dr. Niels Olsen Saraiva Câmara, Dr. José Alexandre Marzagão Barbuto, Dra.

Cibele Peroni, e seus alunos Rodrigo Nalio Ramos, Danilo Candido Almeida, Ênio Bassi e Roberto Gonzalez e colaborador Jean Peron pela amizade, incentivo e apoio em todas as fases deste projeto.

À Dra. Sueli Miyagi Harumi de Cara, pelo companheirismo, risadas, e valiosa amizade.

Aos grandes amigos: Ivana, Roberta, Leila, Stella, Cácio, Niltinho, Renata, Nélio, Andira, Cristiano, Karen, Bruna, Mariana, Talita, Sonia, Meire, Cristiano, Wesley, Vinícius, Carla pelo carinho, companherismo e valiosa amizade em todos os momentos.

À Débora, pela paciência, amizade e cuidados de "mãe".

Aos funcionários da Faculdade de Odontologia e do Instituto de Ciências Biomédicas da USP por todo apoio e amizade em todos os momentos.

Aos funcionários da Secretaria de Pós-graduação em Biotecnologia da USP: Fábia, Eliane e Marcos, por todo apoio e amizade em todos os momentos.

Aos pais de minha namorada, Carlos e Terezinha, pelo carinho e incentivo.

E a todos aqueles que por ventura não foram mencionados aqui, mais que contribuíram para este sonho, meu muitíssimo obrigado.

À Fundação de Amparo à Pesquisa do Estado de São Paulo (FAPESP), agradeço o auxílio financeiro através do projeto de pesquisa 2010/09491-9. 
"A satisfação está no esforço feito para alcançar o objetivo, e não em tê-lo alcançado." 


\section{RESUMO}

Silva FS. Investigação da capacidade imunomoduladora de células-tronco Imaturas de polpa dentária humana. [tese (Doutorado em Biotecnologia)]. São Paulo: Instituto de Ciências Biomédicas, Universidade de São Paulo; 2012.

Células-tronco mesenquimais apresentam propriedades imunomoduladoras com potencial aplicação clínica. As células-tronco imaturas de polpa dentária (CTIPD) são facilmente acessíveis, mas, as suas propriedades imunomoduladoras não foram estudadas. Este presente trabalho objetivou avaliar os efeitos imunomoduladores das CTIPD sobre a diferenciação, maturação das células dendríticas (DC) derivadas de monócitos (mo-DC), sua capacidade para ativar linfócitos T (Lin T), bem como verificar fatores solúveis liberados nos cocultivos celular. CTIPD, células mononucleares do sangue periférico (PBMC) e Lin T foram obtidas a partir de doadores não relacionados $(n=4)$. Monócitos foram obtidos por adesão e remoção de células não aderentes do cultivo de PBMC e foram induzidas a se diferenciarem em moDC por cultura na presença de IL-4 e GM-CSF, durante sete dias. LPS, adicionado após cinco dias de cultura, utilizado para induzir a maturação de mo-DC. Efeitos das CTIPD foram analisados por citometria de fluxo, após a sua adição às culturas a partir do dia zero ou após cinco dias de cultura, a uma proporção de 1:10. Mo-DC expostas às CTIPD desde o dia zero mostraram redução na intensidade média de fluorescência (MFI) dos marcadores BDCA-1 (70\%) e CD11c (32\%) em comparação ao controle; e quando ativadas por LPS, ocorreu a diminuição dos níveis de MFI de CD40 (52\%), CD80 (35\%), CD83 (67\%) e CD86 (50\%), em comparação ao controle. Mo-DC expostas às CTIPD a partir do dia cinco não apresentaram alterações na expressão de marcadores. Para avaliar a capacidade das mo-DC expostas às CTIPD desde o dia zero em ativar respostas em Lin T, mo-DC (HLA-DR+) foram separadas das CTIPD (HLA-DR-), por beads magnéticas, e foram cocultivadas (proporção 1:10) com Lin T (marcadas com CFSE). Após cinco dias, a proliferação das células foi avaliada por diluição de CFSE. A proliferação de Lin T CD4+ induzidas por mo-DC expostas às CTIPD diminuiu em $63 \%$ para mo-DC imaturas (iDC) e em 50\% para mo-DC ativadas por LPS (mDC), em comparação com controle não cultivados com CTIPD. Da mesma forma, a proliferação de Lin T CD8+ diminuiu em $40 \%$ e $26 \%$, em cultura com iDC e mDC, respectivamente, quando cocultivadas com CTIPD. Verificou-se o aumento da proporção de Lin $\mathrm{T}$ CD4+FoxP3+IL-10+ e Lin $\mathrm{T}$ CD4+FoxP3+INF- $\gamma+$ após cocultivo com $\mathrm{mDC}$ previamente cultivadas junto às CTIPD. Os fatores liberados nas coculturas entre as células analisadas apresentaram níveis que refletiram a imunomodulação sofrida pelas células. Foi verificado diminuição nos níveis de fatores pró-inflamatórios como IL-2, TNF- $\alpha$ e IFN- $\gamma$, e o aumento nos níveis do fator anti-inflamatório IL-10. Este estudo mostrou que CTIPD afeta a diferenciação de mo-DC, um fenômeno que se reflete na redução de marcadores de maturação de mo-DC e por uma diminuição da capacidade mo-DC em induzir a proliferação de Lin T. Observações apoiadas pelo balanço anti-inflamatório dos fatores liberados ao meio. A futura caracterização desses fenômenos pode suportar o uso das CTIPD em uma abordagem imunomoduladora utilizando DC em aplicações clínicas.

Palavras-chave: Células-tronco. Células Dendríticas. Diferenciação. Imunomodulação. Linfócitos T. 


\begin{abstract}
Silva FS. Investigation of immunomodulatory capacity of human immature dental pulp stem cells. [Ph. D. thesis (Biotechnology)]. São Paulo: Instituto de Ciências Biomédicas, Universidade de São Paulo; 2012.

Mesenchymal stem cells have immunomodulatory properties with clinical application potential. Immature Dental Pulp Stem cells (IDPSC) are easily accessible, but their immunomodulatory properties have not been studied. This study aimed to evaluate the immunomodulatory effects of IDPSC on differentiation, maturation of dendritic cells (DC) derived from monocytes (mo-DC), their ability to activate $\mathrm{T}$ cells and check soluble factors released in co-culture cells. IDPSC, peripheral blood mononuclear cells (PBMC) and T cells were obtained from unrelated donors $(n=4)$. Monocytes were obtained by adherence and removing non-adherent cells from the PBMC cultivation and were induced to differentiate into mo-DC by culture in presence of IL-4 and GM-CSF for seven days. LPS, added after five days of culture was used to induce maturation of mo-DC. Effects of IDPSC were analyzed by flow cytometry after its addition to the cultures from day zero or after five days of culture at a ratio of 1:10. mo-DC exposed to IDPSC from day zero showed a reduction in mean fluorescence intensity (MFI) of the markers BDCA-1 (70\%) and CD11c (32\%) compared to the control, and when activated by LPS, there was a decrease in MFI of CD40 levels (52\%), CD80 (35\%), CD83 (67\%) and CD86 (50\%) compared to the control. mo-DC exposed to IDPSC from day five showed no changes in the expression of markers. To assess the ability of mo-DC exposed to IDPSC from day zero in activating T cells responses, mo-DC (HLA-DR +) were separated from IDPSC (HLA-DR-) by magnetic beads and were co-cultured (ratio 1:10) with T cells (CFSE-labeled). After five days, cell proliferation was assessed by CFSE dilution. The proliferation of CD4+ T cells induced by mo-DC (exposed to IDPSC) decreased $63 \%$ for immature mo-DC (iDC) and $50 \%$ for mo-DC activated by LPS (mDC), compared to control non-cultivated with IDPSC. Similarly, the proliferation of CD8+ T cells decreased $40 \%$ and $26 \%$ by culture with iDC and $\mathrm{mDC}$, respectively, when co-cultured with IDPSC. There was an increase in the proportion of CD4+FoxP3+IL-10+ $\mathrm{T}$ cells and CD4+FoxP3+IFN- $\gamma+\mathrm{T}$ cells after co-culture with mDC previously cultivated with IDPSC. Soluble Factors released in co-cultures analyzed had levels that reflected the immunomodulation suffered by the cells. It was observed reduction in the levels of proinflammatory factors such as IL-2, TNF- $\alpha$ and IFN- $\gamma$, and increased levels of antiinflammatory factor IL-10. This study showed that IDPSC affects the differentiation of mo$\mathrm{DC}$, a phenomenon that is reflected in the reduction of markers of mo-DC maturation and a decreased ability to mo-DC to induce the T cells proliferation. Observations supported by the anti-inflammatory balance of factors released to the medium. The future characterization of these phenomena can support the use of IDPSC in an immunomodulatory approach using DC in clinical applications.
\end{abstract}

Keywords: Stem cells. Dendritic cells. Differentiation. Immunomodulation. T cells. 


\section{LISTA DE FIGURAS}

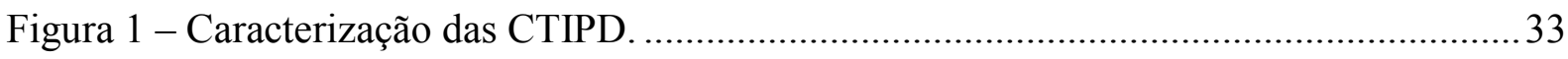

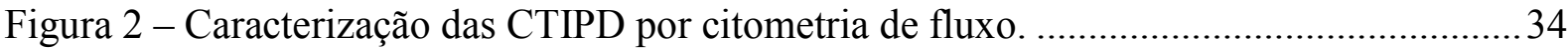

Figura 3 - CTIPD cultivadas em meio para diferenciação e maturação de DC........................35

Figura 4 - Análise da imunomodulação promovida pelas CTIPD sobre as iDC . .................... 37

Figura 5 - Análise da imunomodulação promovida pelas CTIPD sobre as mDC...................39

Figura 6 - Rendimento das mo-DC purificadas por beads magnéticas após a cocultura com

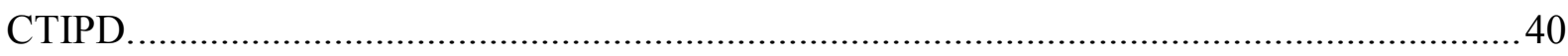

Figura 7 - Análise Funcional das mo-DC [CTIPD] sobre a proliferação de Lin T. ............... 41

Figura 8 - Análise de Lin T CD4+ quanto a marcação para FoxP3, IL-10 e IFN- $\gamma$................ 43

Figura 9 - Níveis de fatores solúveis do cocultivo entre mo-DC e CTIPD. ...........................45

Figura 10 - Níveis de fatores solúveis do cocultivo entre mo-DC[CTIPD] e Lin T...............47 


\section{LISTA DE TABELAS}

Tabela 1 - Desenho experimental da cocultura entre CTIPD e mo-DC utilizando placas de 12 poços para uma quantidade de $2 \times 10^{5} \mathrm{DC}$ 26

Tabela 2 - Desenho experimental da cocultura entre mo-DC e CNA utilizando placas de 96 poços. Entre parênteses estão os grupos de mo-DC que foram previamente cocultivadas com CTIPD 


\section{LISTA DE QUADROS}

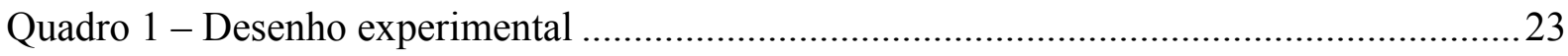

Quadro 2 - Anticorpos anti-humanos utilizados para a caracterização fenotípica das CTIPD e

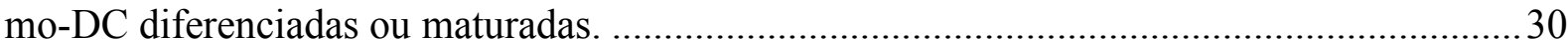




\section{LISTA DE ABREVIATURAS E SIGLAS}
APC
Do inglês antigen-presenting cells
CBA
Do inglês, Cytometric Bead Array
CNA
Células não Aderentes
ConA
Concanavalina A
CT
Células-Tronco
CTA
Células-Tronco Adultas
CTE
Células-Tronco Embrionárias
CTM
Células-Tronco Mesenquimais
CTMO
Células-Tronco Mesenquimais da Medula Óssea
CTPD
Células-Tronco da Polpa Dentária
CTIPD
Células-Tronco Imaturas da Polpa Dentária
d0
Dia zero
d5
Dia cinco
DC
Do inglês, Dendritic cells
GVHD
Do inglês, Graft-versus-host disease
EGF
Do inglês, Epidermal growth factor
EGFR
Do inglês, Epidermal growth factor receptor
HGF
Do inglês, Hormone growth Factor
iDC
DC imaturas
iDC[CTIPD]
DC imaturas pré-cultivadas com CTIPD
IFN- $\gamma$
Do inglês, Interferon $\gamma$
IL
Do inglês, interleukin
LPS
Lipolisacarídeo bacteriano
LTC
Linfócitos T Citotóxicos
MCP-1
Do inglês monocyte chemoattractant protein-1
$\mathrm{mDC}$
DC maduras
$\mathrm{mDC}[\mathrm{CTIPD}]$
DC maduras pré-cultivadas com CTIPD
MHC
Do inglês, major histocompatibility complex
mo-DC
DC derivadas de monócitos
NK
Do inglês, natural killer
PGE2
Prostaglandina E2 
PHA

Do inglês, phytohemagglutinin A

TGF

Do inglês, Tumor Growth Factor

TNF- $\alpha$

Do inglês tumor necrosis factor $\alpha$ 
1 INTRODUÇÃO

1.1 As células-tronco mesenquimais modulam a resposta imunológica .......................... 17

1.2 Moléculas imunomoduladoras e resposta celular .................................................... 19

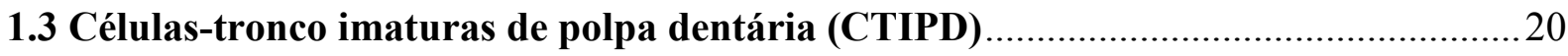

1.4 As células-tronco de polpa dentária e seu potencial imunossupressor .......................20

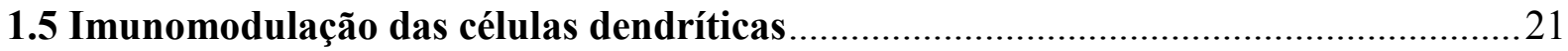

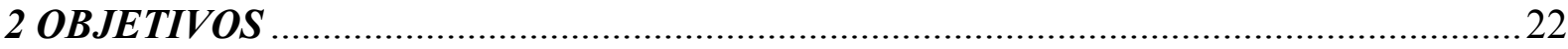

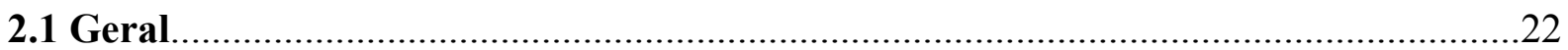

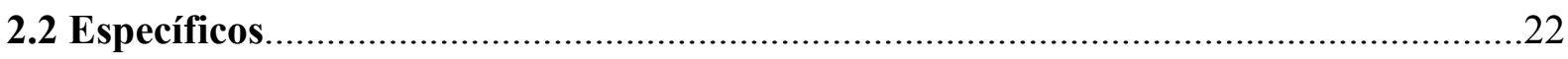

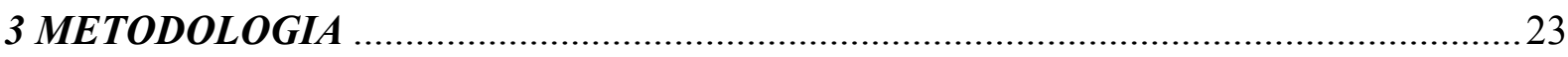

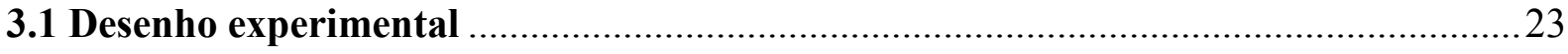

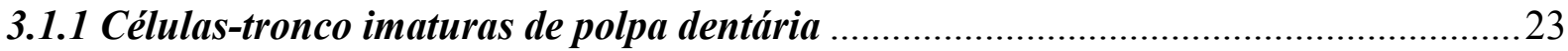

3.1.2 Caracterização das células-tronco imaturas de polpa dentária ..................................24

3.1.3 Isolamento das populações de células mononucleares de sangue periférico...............25

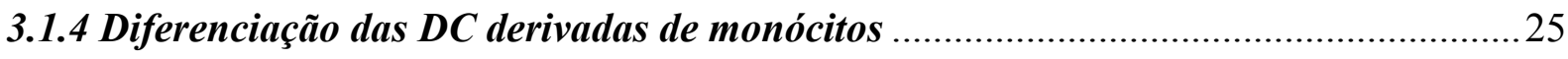

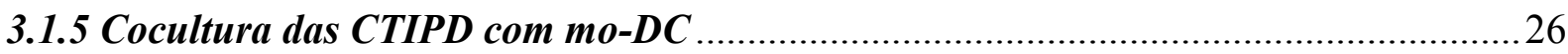

3.1.6 Funcional das mo-DC cultivadas com CTIPD: ensaio de proliferação de linfócitos

3.1.7 Análise por citometria de fluxo: marcação celular .................................................28

3.1.8 Mensuração de fatores solúveis das coculturas de CTIPD:DC e DC:Lin T ............... 31

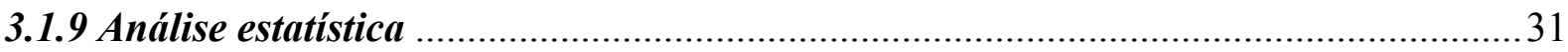

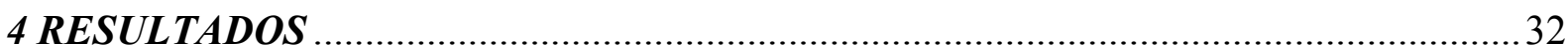

4.1 Células-Tronco Imaturas de Polpa Dentária e sua caracterização ............................. 32

4.2 Isolamento das populações de células mononucleares de sangue periférico ............... 36

4.3 Funcional das DC cultivadas com CTIPD: ensaio de proliferação de linfócitos T..... 40

4.4 Avaliação da população Lin T CD4+FoxP3+ e citocinas intracelular IL-10 e IFN- $\gamma 42$

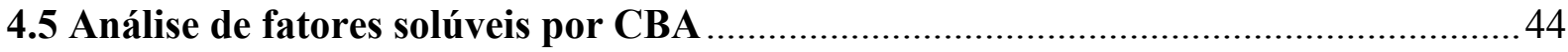

5 DISCUSSÃO

REFERÊ 


\section{INTRODUÇÃO}

As células-tronco (CT) apresentam duas características fundamentais que são a capacidade de autorrenovação e o potencial para diferenciar em múltiplas linhagens de celulares (Kerkis et al., 2006). Em contraste com a natureza pluripotente das células-tronco embrionárias (CTE), acreditava-se que as células-tronco adultas (CTA) apresentavam potencial de diferenciação mais restrito. Entretanto, hoje isso vem sendo discutido. As células-tronco mesenquimais (CTM) são um tipo de CTA e podem ser isoladas da medula óssea, tecido adiposo (Aggarwal et al., 2005), músculo esquelético (Dzionek et al., 2000), sinóvia (Oyoshi et al., 2006), baço, timo (Maus et al., 2001), sangue, pulmão, sangue fetal (von Wulffen et al., 2007) e líquido amniótico (Lai et al., 2010). A literatura científica mostra que as CTM apresentam potencial de diferenciação in vitro, originando várias células tecido específico, tais como osteoblastos, condrócitos, e adipócitos (Ortiz et al., 2013, Yan et al., 2007), músculo (van den Brink et al., 2002), precursores neuronais (Li et al., 2008, Maldonado-Lopez et al., 2001) e cardiomiócitos (Gronthos et al., 2000, Oyoshi et al., 2008, van den Berk et al., 2009). Estudos usando modelos animais mostraram, além do potencial de regeneração, a capacidade das CTM em migrarem para os locais onde há tecidos injuriados (Pierdomenico et al., 2005, van der Valk et al., 2010, Zhang et al., 2004). Existem também trabalhos que relatam que essas células são capazes de fornecer suporte como fatores de crescimento para expansão de células-tronco hematopoiéticas e embrionárias (Angelot et al., 2009, Nimmerjahn et al., 2006, Ravetch et al., 2001, Vermaelen et al., 2004).

\subsection{As células-tronco mesenquimais modulam a resposta imunológica}

A interação de CTM com células do sistema imunológico de resposta inata e adaptativa tem sido investigada in vitro (Aggarwal et al., 2005, Bartholomew et al., 2002, Glennie et al., 2005, Krampera et al., 2003, Le Blanc et al., 2003a). Esta abordagem tem permitido uma melhor compreensão dos dois principais meios pelos quais as CTM modulam o sistema de resposta imunológico: (1) por contato célula-célula e (2) secreção de moléculas reguladoras.

Bartholomew et al. (2002) demonstraram que as CTM isoladas de babuíno suprimiram a proliferação de linfócitos estimulados com Concavalina A (ConA) e que essa supressão foi dependente da dose celular. A observação que a proliferação das células $\mathrm{T}$ é inibida pelas 
CTM, sugere que essas células não expressam o MHC de classe II. Recentes evidências demonstram que as CTM indiferenciadas expressam níveis intermediários de MHC Classe I, mas não expressam MHC de classe II ou moléculas coestimuladoras, tais como CD40, B7-1 e B7-2 (Le Blanc et al., 2003a, b). Além disso, as CTM mantêm sua capacidade imunossupressora, mesmo após a sua diferenciação para as linhagens adipogênica, condrogênica e osteogênica (Iyer et al., 2008). Clinicamente, isto significa que as CTM indiferenciadas e diferenciadas são adequadas para o transplante, mesmo entre indivíduos com MHC incompatíveis. Dessa forma, é sugerido que as CTM escapam do reconhecimento dos linfócitos T citotóxicos (CTL) (Rasmusson et al., 2007). Também é observado que as CTM podem diminuir a ativação de CTL e impedir a expressão de citocinas pró-inflamatórias como interferon- $\gamma$ (IFN- $\gamma$ ) e fator de necrose tumoral $\alpha$ (TNF- $\alpha$, do inglês tumor necrosis factor $\alpha)$.

A capacidade de CTM de interagirem diretamente com as células imunológicas e secretarem moléculas reguladoras tornam essas células atraentes candidatas em aplicações terapêuticas visando à regulação da resposta inflamatória, de infecções e lesões. Diversos estudos em animais demonstraram que a administração de CTM aumentou a reparação tecidual, além de facilitar a regeneração do tecido lesionado. Estes efeitos parecem ser mediados por fatores solúveis produzidos pelas CTM. Os efeitos imunomoduladores das CTM foram demonstrados em modelos animais com lesões, incluindo lesão miocárdica (Ohnishi et al., 2007), isquemia renal e reperfusão (Semedo et al., 2007), insuficiência hepática (Parekkadan et al., 2007), encefalomielite autoimunes (Gerdoni et al., 2007) e feridas causadas por queimaduras (Rasulov et al., 2006). Ohnishi et al. (2007) relataram que a administração das CTM por via intravenosa em ratos durante o quadro de miocardite aguda diminuía os níveis da proteína-1 quimiotática de monócitos (do inglês monocyte chemoattractant protein-1 - MCP-1) no miocárdio, tendo como consequência o aumento da angiogênese e melhora na função cardíaca (Ohnishi et al., 2007). Ratos tratados com Dgalactosamina, uma hepatotoxina, receberam meio condicionado do cultivo de CTM resultando numa diminuição significativa da infiltração de leucócitos no fígado, comparado com o meio condicionado em fibroblastos (Parekkadan et al., 2007). A eficácia das CTM na atenuação de dano renal provocado por isquemia e reperfusão em ratos também foi documentada (Semedo et al., 2007). Observou-se que a creatinina sérica e níveis de uréia plasmática foram normalizados dentro de 24 h após infusão de CTM; os níveis de IL-1 $\beta$, uma citocina pró-inflamatória, diminuíram, enquanto os níveis de IL-4, uma citocina antiinflamatória, aumentaram no tecido renal. Em relação à doença do enxerto contra o 
hospedeiro (do inglês Graft-versus-host disease - GVHD), resultados com pacientes submetidos a transplante de medula óssea administrados com CTM alogênicas sugeriram que CTM protegiam contra GVHD (Ringdén et al., 2006).

\subsection{Moléculas imunomoduladoras e resposta celular}

Existem muitas moléculas ligadas à resposta imunológica, elas são classificadas em pró-inflamatórias e anti-inflamatórias e estão ligadas com a imunomodulação de determinados tipos celulares. A GVHD envolve uma fisiopatologia que inclui dano ao tecido hospedeiro, aumento da secreção de citocinas pró-inflamatórias (TNF- $\alpha$, IFN- $\gamma$ IL-1, IL-2, IL-12), além da ativação de células dendríticas (DC do inglês dendritic cells), macrófagos, células T Natural Killer (NK), e Linfócitos T citotóxica (van den Brink et al., 2002).

A inibição da secreção de TNF- $\alpha$ por DC inibe a maturação, migração para os linfonodos e a capacidade de estimular linfócitos T, alterando a expressão de diversos receptores e correceptores necessários para a captura e processamento de antígeno (Abe et al., 2003, Maldonado-Lopez et al., 2001, Ritter et al., 2003). Zhang et al. (2004) observaram em cocultura de CTM:DC que as CTM inibiam a regulação de vários marcadores de maturação de DC, resultando na diminuição da sua capacidade de ativar as células T reativas. Aggarwal et al. (2005), mostraram que as CTM, devido à sua capacidade de inibir a secreção de TNF- $\alpha$ pelas DC, levam a um estado de tolerância imunológica. Os dados in vitro sugerem que CTM, e sua capacidade tanto de inibir IFN- $\gamma$ quanto aumentar a secreção de IL-4, pode orquestrar uma mudança da proeminência de células pró-inflamatórias Th1 em direção a um aumento de células anti-inflamatórias Th2, o que pode ser benéfico para o tratamento de GVHD. As CTM constitutivamente expressam fatores tolerogênicos, tais como o fator de crescimento de hepatócito (HGF), IL-10 e fator de crescimento tumoral $\beta 1$ (TGF- $\beta 1$ ). A administração do HGF, IL-10 e TGF- $\beta 1$ suprimem a proliferação de linfócitos (Ryan et al., 2007). Contudo, o bloqueio de cada um desses fatores isoladamente ou em combinação não revoga o efeito antiproliferativo da CTM, indicando que CTM utiliza outros mediadores distintos para suprimir a proliferação de células T. Um destes mediadores é a prostaglandina E2 (PGE2), um produto enzimático de metabolismo do ácido araquidônico. PGE2 é constitutivamente expressa em CTM em cultura (Ryan et al., 2007). Curiosamente, a produção da PGE2 é dramaticamente aumentada em CTM após estimulação com ou TNF- $\alpha$ ou IFN- $\gamma$, e inibição da síntese de PGE2 revoga os efeitos antiproliferativos de CTM em linfócitos (Ryan et al., 
2007). Níveis de PGE2 também estavam aumentados, mesmo as CTM sendo cultivadas sobre meio de diferenciação para adipócitos (Aggarwal et al., 2005, Maldonado-Lopez et al., 2001).

\subsection{Células-tronco imaturas de polpa dentária (CTIPD)}

As células-tronco da polpa dentária (CTPD) são capazes de se diferenciarem in vivo em osso, cartilagem e dentina, e já foram isoladas tanto de humanos quanto de camundongos (Caplan et al., 1991, Yamamura, 1985). Estudos mais aprofundados de uma população mais restrita de CTPD humana demonstraram uma rápida expansão e proliferação in vitro e, no estado indiferenciado, demonstraram a expressão de alguns marcadores de células-tronco mesenquimais, tais como o STRO-1 e CD146 (Miura et al., 2003). Após a indução da diferenciação in vitro, em condições de cultivo apropriado e utilizando agentes indutores de diferenciação, foi possível a produção de células neuronais, adipócitos e odontoblastos e a formação especializada de dentina e osso após o transplante em camundongo (Abott, 2000, Gronthos et al., 2000, Miura et al., 2003).

\subsection{As células-tronco de polpa dentária e seu potencial imunossupressor}

Muitos estudos têm mostrado o efeito imunomodulador das CTM derivadas da medula óssea (CTMO). Contudo, poucos trabalhos têm mostrado a capacidade imunomoduladora das CTPD. Pierdomenico et al. (2005) compararam a capacidade imunomoduladora entre CTMO e CTPD. A função imunomoduladora foi testada em cocultura com células T, estimuladas com fitohemaglutinina (do inglês, phitobehamitin - PHA); as CTPD se mostraram mais imunomoduladoras que as CTMO. Ainda, as CTPD isoladas de dentes decíduos esfoliados, e denominadas aqui como células-tronco imaturas de polpa dentária (CTIPD), inibiram a proliferação de linfócitos Th17 também com mais eficiência em comparação com as CTMO (Yamaza et al., 2010). O fato das CTIPD serem isoladas de dentes decíduos e de alguns trabalhos mostrarem que estas células expressam Nestin (molécula presente em células da linhagem neuronal e em células originadas da crista neuronal embrionária) e Oct-4 (marcador embrionário), acredita-se que as CTIPD possuem a facilidade de se diferenciarem para células das linhagens mesenquimais e ectodermais (Chai et al., 2000, Huang et al., 2009, Miura et al., 2003, Yamaza et al., 2010). Em modelo murino de lúpus eritematoso, CTIPD e CTMO foram capazes de atenuar a autoimunidade causada por esta doença, evidenciado pelo decréscimo 
dos níveis de autoanticorpos, da creatinina presente no soro e urina e de níveis de proteínas presentes na urina (Yamaza et al., 2010).

\subsection{Imunomodulação das células dendríticas}

As DC são de grande importância no contexto geral do inicio da reação imune, desde que são as principais células apresentadoras de antígenos (do inglês, antigen-presenting cells APC) responsáveis por iniciar a resposta imune adaptativa junto com macrófagos e ativação de Lin T e B; sendo os principais participantes do inicio da inflamação aguda, regulação do balanço de Lin Th1/2 e T reguladoras (Treg), atuando nos processos de tolerância e rejeição (Aggarwal et al., 2005, Lai et al., 2010, Lanzavecchia, Sallusto, 2004, Yamaza et al., 2010).

Lai et al. (2010) observaram que as CTMO diminuíram a diferenciação de células progenitoras para DC em experimento de cocultura. Em cocultura de CTMO:DC, Zhang et al. (2004) mostraram a inibição da regulação de moléculas de superfície relacionadas à maturação de DC, diminuindo a função em ativar Lin T. Devido a habilidade das CTMO em inibir a secreção de TNF- $\alpha$ pelas DC, Aggarwal et al. (2005) mostraram que as CTMO eram responsáveis por um estado de tolerância imunológica. Experimentos in vitro sugerem que as CTMO, com sua capacidade de inibir IFN- $\gamma$ e aumentar a secreção de IL-4, deve orquestrar a mudança de um estado pró-inflamatório em direção a um estado anti-inflamatório, beneficiando assim muitos tratamentos, por exemplo, doença do hospedeiro versus enxerto.

Muito estudos verificaram que as CTM possuem grande potencial imunomodulador trazendo muitas possibilidades para tratamentos de doenças relacionadas aos processos imunes. Dessa forma, este estudo objetiva acrescentar mais conhecimento sobre o aspecto imunomodulador das CTIPD frente à diferenciação e maturação das DC derivadas de monócitos (mo-DC), avaliar se a imunomodulação sofrida pelas mo-DC altera sua funcionalidade em ativar Lin T CD4+ e Lin T CD8+, bem como verificar fatores solúveis presente no sobrenadante das coculturas celulares. 
2 OBJETIVOS

\subsection{Geral}

Avaliar in vitro a ação imunomoduladora mediada pelas CTIPD em cocultivo com mo-DC.

\subsection{Específicos}

1) Avaliar a capacidade imunomoduladora das CTIPD na diferenciação e maturação das DC derivadas de monócitos, pela marcação de moléculas de superfície;

2) verificar a função das mo-DC, pré-cultivadas com CTIPD, em induzir a proliferação de Lin T CD4+ e Lin T CD8+;

3) verificar se Lin T CD4+ cocultivadas com mo-DC, pré-cultivadas com CTIPD, apresentam mudança na marcação de FoxP3, IL-10 e INF- $\gamma$;

4) avaliar o perfil dos mediadores solúveis pró-inflamatórios e anti-inflamatórios presentes no meio de cultivo após cocultivo entre mo-DC e CTIPD e entre mo-DC, pré-cultivadas com CTIPD, e Lin T. 


\section{METODOLOGIA}

\subsection{Desenho experimental}

Os experimentos foram realizados de acordo com o desenho experimental esquematizado no Quadro 1.

Quadro 1 - Desenho experimental

\begin{tabular}{|c|c|}
\hline Caracterização das CTIPD & Análise \\
\hline Diferenciação & $\begin{array}{l}\text { Osteogênica } \\
\text { Adipogênica }\end{array}$ \\
\hline \multirow[t]{2}{*}{ Fenotipagem } & Marcadores hematopoiéticos: CD34 e CD45 \\
\hline & $\begin{array}{l}\text { Marcadores mesenquimais: CD73, CD90 e } \\
\text { CD105 }\end{array}$ \\
\hline Cocultivo & Análise \\
\hline CTIPD:DC Imaturas & \multirow{2}{*}{$\begin{array}{l}\text { Citometria: BDCA1, CD11c, CD14, CD40, } \\
\text { CD80, CD83, CD86, HLA-DR } \\
\text { CBA: IL-2, IL-4, IL-6, IL-10, IL-17, TNF- } \alpha \text { e } \\
\text { INF- } \gamma\end{array}$} \\
\hline CTIPD:DC Maturas & \\
\hline Lin T:DC Imaturas (pré-cultivadas com CTIPD) & \multirow{2}{*}{$\begin{array}{l}\text { Citometria: Proliferação para Lin T CD4+, Lin } \\
\text { T CD8+; marcação para Foxp3, IL-10 e IFN- } \gamma \text {. } \\
\text { CBA: IL-2, IL-4, IL-6, IL-10, IL-17, TNF- } \alpha \text { e } \\
\text { INF- } \gamma\end{array}$} \\
\hline Lin T:DC Maturas (pré-cultivadas com CTIPD) & \\
\hline
\end{tabular}

CBA - Cytometric Bead Array

\subsubsection{Células-tronco imaturas de polpa dentária}

Os experimentos foram realizados em colaboração com três laboratórios: Laboratório de Pesquisa Básica, que tem como responsável a Profa. Dra. Márcia Martins Marques, e que está localizado no Departamento de Dentística, Faculdade de Odontologia da USP - FOUSP; Laboratório de Imunologia de Transplantes, sob responsabilidade do Dr. Niels Olsen Saraiva Câmara, localizado no departamento de Imunologia, Instituto de Ciências Biológicas da USP

- ICB/USP; Laboratório de Imunologia de Tumores, sob responsabilidade do Dr. José Alexandre Marzagão Barbuto, ICB/USP.

O projeto de pesquisa teve aprovação do comitê de ética, parecer número 129/10 (FOUSP), para doação de dentes e sangue periférico. 
As CTIPD foram obtidas de dentes decíduo esfoliado humano extraídos de um doador (após a assinatura do Termo de Consentimento Livre e Esclarecido - TCLE; sendo a identidade do doador mantida em sigilo), e o processamento da polpa dentária foi realizada de acordo com o protocolo descrito por Gronthos et al. (2000). As CTIPD foram cultivadas em garrafas de $25 \mathrm{~cm}^{2}$ ou $75 \mathrm{~cm}^{2}$ em meio basal constituído de meio DMEM-F12 (Invitrogen, CA) suplementado com 15\% (v/v) de soro Hyclone (Thermo, EUA), 100 U/mL de penicilina e $100 \mu \mathrm{g} / \mathrm{mL}$ de estreptomicina, $2 \mathrm{mM}$ de L-glutamina e 0,01 $\mathrm{mM}$ de aminoácidos não essenciais (Invitrogen, EUA). A cultura foi mantida a $37^{\circ} \mathrm{C}$ a uma atmosfera umidificada contendo $95 \%$ de ar e 5\% CO2, até atingir confluência máxima de 70\%, quando ocorria o repique ou congelamento em nitrogênio líquido utilizando o meio de congelamento constituído por DMEM-F12 suplementado com $20 \%$ (v/v) de SFB e 10\% (v/v) de DMSO (Sigma, EUA). O acompanhamento do crescimento celular e sua morfologia foram feitos por microscopia de luz transmitida (Nikon TS100F, Japão).

\subsubsection{Caracterização das células-tronco imaturas de polpa dentária}

A caracterização fenotípica das CTIPD foi realizada pela marcação para as moléculas descritas no Quadro 2 e a análise feita por citometria de fluxo (BD FACSCanto II Flow Cytometer, BD Biosciences, EUA). A marcação foi feita para uma quantidade de $1 \times 10^{5}$ células.

As CTIPD foram submetidas à diferenciação osteogênica e adipogênica. Inicialmente foram semeadas em placas de 24 poços e cultivadas em meio basal a $37{ }^{\circ} \mathrm{C}$ a $5 \%$ de $\mathrm{CO} 2$. Ao atingirem $100 \%$ de confluência o meio foi trocado para o meio de diferenciação osteogênica ou adipogênica seguindo as instruções do fabricante do kit Mesenchymal Stem Cell Osteogenesis ou Mesenchymal Stem Cell Adipogenesis Kit (Millipore, EUA), respectivamente. A cada três dias o meio de diferenciação foi trocado durante os 21 dias de cultivo. Após esse período, as células foram coradas com vermelho de Alizarina para avaliação da diferenciação osteogênica ou coradas com Oil Red-O para a diferenciação adipogênica; seguindo as instruções do fabricante dos kits acima citados. 


\subsubsection{Isolamento das populações de células mononucleares de sangue periférico}

A coleta do sangue periférico foi feita por punção venosa utilizando tubos Vacuteiners ${ }^{\circledR}$ contendo heparina (BD Bioscience, EUA). Após a aprovação do Comitê de Ética 129/10 (FOUSP) e assinatura do TCLE, sendo a identidade dos doadores mantida em sigilo. Imediatamente após a coleta, $32 \mathrm{~mL}$ de sangue de cada doador foram divididos em dois tubos de polipropileno de $50 \mathrm{~mL}$ (Corning, EUA). Células mononucleares de sangue periférico humano (do inglês, peripheral blood mononuclear cells - PBMC) foram isoladas por centrifugação por densidade de gradiente utilizando $12 \mathrm{~mL}$ de Ficoll-Paque (densidade 1,077g/ml; BD Bioscience, EUA). As células foram centrifugadas utilizando centrifuga (Eppendorf, Alemanha) na configuração de raio do rotor $14.5 \mathrm{~cm}, 900 \mathrm{~g}$, por 30 minutos. Após a centrifugação as PBMC foram colhidas e passadas para um novo tubo de polipropileno. As células foram lavadas três vezes com $40 \mathrm{~mL}$ de meio RPMI (Gibco, EUA), sendo a centrifugação da primeira lavagem a $600 \mathrm{~g}$ e as subsequentes a $300 \mathrm{~g}$, por 10 minutos, utilizando $18 \mathrm{~cm}$ de raio do rotor. As células foram ressuspendidas em meio R10 composto por meio RPMI, suplementado com $10 \%$ (v/v) de soro fetal bovino (SFB; Gibco, EUA) e antibiótico $(100 \mathrm{U} / \mathrm{mL}$ de penicilina, $100 \mu \mathrm{g} / \mathrm{mL}$ de estreptomicina e $25 \mu \mathrm{g} / \mathrm{mL}$ de anfotericina B; Gibco, EUA) e contadas utilizando hemocitômetro.

\subsubsection{Diferenciação das DC derivadas de monócitos}

As PBMC foram semeadas em meio R10 e mantidas em estufas de $\mathrm{CO} 2$ a $37{ }^{\circ} \mathrm{C}$ e $5 \%$ de $\mathrm{CO} 2$ por 90 minutos. Em seguida as células não aderentes (CNA) foram removidas pela coleta do sobrenadante e congeladas em meio contendo RPMI, $20 \%$ (v/v) de SFB e $10 \%$ (v/v) de DMSO (Sigma, EUA) para o posterior uso no ensaio de proliferação de linfócitos.

Os monócitos que permaneceram aderidos foram cultivados em meio R10 suplementado com IL-4 (50 ng/mL, R\&D Systems, EUA) e GM-CSF (50 ng/mL, R\&D Systems, EUA) por cinco dias para diferenciação para DC imaturas (iDC). As iDC diferenciadas foram cultivadas por mais dois dias na presença de $50 \mu \mathrm{g} / \mathrm{mL}$ de lipopolissacarídeo (LPS; sorotipo O111:B4, Sigma, EUA) para gerar DC maturadas (mDC). A avaliação da diferenciação e maturação das mo-DC foi realizada por citometria de fluxo utilizando marcadores descritos no Quadro 2. 


\subsubsection{Cocultura das CTIPD com mo-DC}

A cocultura entre CTIPD e mo-DC (células de doadores não parentados) foram realizadas nas proporções indicadas na Tabela 1 em relação a quantidade de $2 \times 10^{5} \mathrm{DC}$ em placa de 12 poços (Corning, EUA), seguindo os protocolos modificados de Aggarwal et al. (2005), Angelot et al. (2009), Choi et al. (2012), Ramos et al. (2012) e Zhang et al. (2004). Os experimentos foram divididos em cocultura desde o dia zero (d0) e depois de 5 dias de cultivo (d5) em combinação CTIPD:iDC ou CTIPD:mDC. A influência imunomoduladora das CTIPD foi avaliada ao serem adicionadas na cultura de mo-DC desde o dia zero (iDC ou d0 ou $\mathrm{mDC}$ d0) ou após cinco dias (iDC d5; e mDC d5), período onde é adicionado o LPS para maturação das CDs. Os experimentos foram realizados em quadruplicata.

Tabela 1 - Desenho experimental da cocultura entre CTIPD e mo-DC utilizando placas de 12 poços para uma quantidade de $2 \times 10^{5} \mathrm{DC}$.

\begin{tabular}{|c|c|c|c|}
\hline Grupos & $\begin{array}{l}\text { Proporção } \\
\text { CTIPD:DC }\end{array}$ & Presença das CTIPD & Maturação aos cinco dias de cultivo \\
\hline $\begin{array}{l}\text { Controle } \\
\text { iDC d0 }\end{array}$ & $\begin{array}{l}\text { iDC sem } \\
\text { CTIPD }\end{array}$ & --- & --- \\
\hline iDC d0 & $\begin{array}{c}1: 10 \\
1: 20 \\
1: 100\end{array}$ & d0 & --- \\
\hline iDC d5 & $\begin{array}{c}1: 10 \\
1: 20 \\
1: 100\end{array}$ & d5 & --- \\
\hline $\begin{array}{l}\text { Controle } \\
\mathrm{mDC} \text { d0 }\end{array}$ & mDC sem CTIPD & --- & LPS \\
\hline $\mathrm{mDC} \mathrm{d} 0$ & $\begin{array}{c}1: 10 \\
1: 20 \\
1: 100\end{array}$ & d0 & LPS \\
\hline $\mathrm{mDC} \mathrm{d} 5$ & $\begin{array}{c}1: 10 \\
1: 20 \\
1: 100\end{array}$ & d5 & LPS \\
\hline
\end{tabular}

No final da cocultura as células foram removidas para análise por citometria de fluxo dos marcadores para monócitos ou células precursoras mieloides, mo-DC imaturas ou maturas, de acordo com o Quadro 2; e o sobrenadante armazenados em tubos de $500 \mu \mathrm{L}$ para posterior análise por CBA para fatores solúveis no meio de cultura. 
Para verificar se as CTIPD diferenciaram para DC, foram cultivadas em meio de diferenciação para DC, na presença de LPS, e analisadas para marcadores de monócitos e moDC, precursoras, imaturas e maturas.

\subsubsection{Funcional das mo-DC cultivadas com CTIPD: ensaio de proliferação de linfócitos}

Após a cocultura das mo-DC com CTIPD, foi verificado que os grupos iDC e mDC que receberam CTIPD desde o dia zero, na proporção de 1:10 (CTIPD:mo-DC; ver Tabela 1) apresentaram os resultados mais expressivos, portanto, esses grupos foram selecionados para condicionar as mo-DC para posterior cocultivo com CNA.

As mo-DC cocultivadas com CTIPD foram removidas e separadas por beads magnéticas. Previamente verificou-se que as CTIPD não apresentava marcação para HLADR. Uma vez que as DC apresentam a molécula HLA-DR, em sua superfície, utilizou-se antiHLA-DR conjugado com PE e beads anti-PE, como secundário, para seleção por MiniMACS ${ }^{\text {TM }}$ Separator, seguindo as instruções do fabricante (Miltenyi Biotec, Alemanha). O rendimento do isolamento foi verificado pela marcação para CD45 (BD Bioscience, EUA). As mo-DC isoladas foram cocultivadas com CNA de doadores não aparentados.

As CNA, previamente criopreservadas, foram descongeladas em meio R10 e processadas em Ficoll-Page para eliminação de células mortas, seguindo o mesmo protocolo descrito acima para a obtenção de PBMC. As CNA foram marcadas com $5 \mu \mathrm{M}$ de Carboxyfluorescein Succinimidyl Ester (CFSE; Invitrogen, EUA), com incubação de 10 minutos a $37^{\circ} \mathrm{C}$, protegido da luz. As células foram lavadas duas vezes em meio R10 gelado, e mantidas em suspensão para o cocultivo com mo-DC.

As mo-DC previamente tratadas com CTIPD e isoladas e as CNA marcadas com CFSE foram cocultivadas numa proporção de 1:10 (1x10 ${ }^{4}$ mo-DC para $\left.1 \times 10^{5} \mathrm{CNA}\right)$ em meio R10 (sem suplementação de IL-4 e GM-CFS) por cinco dias em placas de 96 poços com fundo em "U" (Corning, EUA). Os grupos foram esquematizados de acordo com a Tabela 2 para a determinação da proliferação. Como controle positivo fitohemaglutinina (PHA - do inglês phytohemagglutinin; $1 \mu \mathrm{g} / \mathrm{mL}$; Invitrogen, EUA) foi utilizada para o estímulo proliferativo dos $\mathrm{Lin} \mathrm{T} \mathrm{CD} 4^{+}$ou Lin $\mathrm{T} \mathrm{CD}^{+}$. Os experimentos foram realizados em triplicata. 
Tabela 2 - Desenho experimental da cocultura entre mo-DC e CNA utilizando placas de 96 poços. Entre parênteses estão os grupos de mo-DC que foram previamente cocultivadas com CTIPD.

\begin{tabular}{|c|c|c|c|}
\hline \multirow[t]{3}{*}{ Grupos } & \multirow[t]{3}{*}{ Estímulo } & \multicolumn{2}{|c|}{ Análises } \\
\hline & & & Sobrenadante \\
\hline & & Marcadores & Citocinas \\
\hline iDC & & & CBA \\
\hline iDC[CTIPD] & & & CBA \\
\hline $\mathrm{mDC}$ & & & CBA \\
\hline $\mathrm{mDC}[\mathrm{CTIPD}]$ & & & CBA \\
\hline CNA & & Citometria (-) & CBA \\
\hline CNA & PHA & Citometria (+) & CBA \\
\hline CNA & & Citometria (M) & CBA \\
\hline CNA & PHA & Citometria (M) & CBA \\
\hline iDC:CNA & & Citometria (M) & CBA \\
\hline iDC[CTIPD]:CNA & & Citometria (M) & CBA \\
\hline mDC:CNA & & Citometria (M) & CBA \\
\hline mDC[CTIPD]:CNA & & Citometria (M) & CBA \\
\hline
\end{tabular}

Entre as chaves estão as mo-DC que foram previamente cocultivadas com CTIPD.

(+): controle positivo com PHA e sem marcação para moléculas CD4 e CD8.

(-): controle negativo sem PHA e sem marcação para moléculas CD4 e CD8.

(M): células marcadas com CD4 e CD8.

CBA: citocinas IL-2, IL-4, IL-6, IL-10, IL-17, TNF- $\alpha$ e PGE2.

Após cinco dias de cocultura as células foram colhidas e marcadas com anticorpos anti-CD4 e anti-CD8 conjugados com os fluorocromos PE e PerCP, respectivamente. A análise celular foi feita por citometria de fluxo. Os sobrenadantes foram colhidos e armazenados em tubos de $500 \mu \mathrm{L}$ a $-70{ }^{\circ} \mathrm{C}$ para posterior análise por CBA para os fatores solúveis.

\subsubsection{Análise por citometria de fluxo: marcação celular}

Marcação de superfície celular. Para a análise de citometria de fluxo, as CTIPD foram lavadas três vez em PBS, desagregadas enzimaticamente utilizando Tripsina (TrypLE Express; Invitrogen, EUA) por cinco minutos a $37{ }^{\circ} \mathrm{C}$, a inativação foi feita com o próprio meio de cultivo. As mo-DC foram ressuspendidas após permanecerem 30 minutos sobre gelo e removidas pela lavagem dos poços com RPMI gelado. Os linfócitos foram recolhidos do cultivo junto com o sobrenadante. As células foram centrifugadas a 300 g por 10 minutos, contadas utilizando hemocitômetro e destinadas a marcação para moléculas de superfície. CTIPD e mo-DC foram marcadas de acordo com o Quadro 2, sendo marcação única para as CTIPD e multimarcação para DC. Para a multimarcações foram realizadas compensações nos 
canais FL1, FL2, FL3 e FL4 utilizando beads marcadas (BD Bioscience, EUA). Lin T presentes nas CNA foram duplamente marcadas para moléculas CD4 (marcador para linfócitos T auxiliares; clone RPA-T4, isotipo IgG1, APC), CD8 (marcador para linfócitos T citotóxicos; clone SK1, isotipo IgG1, PerCP). $1 \times 10^{5}$ células foram lavadas duas vezes por 10 minutos, centrifugadas a $300 \mathrm{~g}$ e a $18{ }^{\circ} \mathrm{C}$ com tampão para citometria (PBS contendo $0,5 \%$ $(\mathrm{p} / \mathrm{v})$ de albumina e $0,02 \%(\mathrm{p} / \mathrm{v})$ de azida sódica). O sobrenadante foi descartado, adicionado 2 $\mu \mathrm{L}$ de cada anticorpo e homogeneizadas brevemente em vórtex. As células foram incubadas, protegidas, da luz, por 20 minutos na geladeira. Em seguida as células foram lavadas duas vezes e ressuspendidas em tampão de citometria contendo $2 \%$ de formaldeído (com exceção dos Lin T que foram lidos logo após a marcação) e conservadas em geladeira até a leitura no citômetro (BD FACSCanto II flow cytometer, BD Biosciences, EUA).

Marcação intracelular para FoxP3. Lin T cocultivados com mDC e destinados para verificação de Lin T positivos para FoxP3, IL-10 e IFN- $\gamma$, proteínas intracelulares tiveram que ser permeabilizadas, para isso seguimos as instruções do kit FoxP3 Fix/Perm Buffer Set (Biolegend, EUA). As células foram ressuspendidas em $100 \mu \mathrm{L}$ de Fix/Perm e incubadas por $20 \mathrm{~min}$ a temperatura ambiente. As células foram lavadas com Cell Stainning Buffer, ressuspendidas em Perm Buffer e incubadas por 15 min. AS células foram novamente ressuspendidas em $100 \mu \mathrm{L}$ de Perm Buffer contendo $1 \mu \mathrm{L}$ do anticorpo FoxP3 (Alexa 488), CD4 (PE) e IL-10 (APC) ou FoxP3 (Alexa 488), CD4 (APC) e INF- $\gamma$ (PE) e foram incubadas por 30 min. As células foram lavadas em Cell Stainning Buffer e analisadas em citometria de fluxo.

A análise da caracterização das CTIPD, da proliferação de Lin T CD4+ e Lin T CD8+, como também para a marcação intracelular para verificar a positividade para FoxP3 e IL-10 ou IFN- $\gamma$ foi feita comparando a porcentagem de células marcadas; para as mo-DC a análise foi feita pela comparação da intensidade média de fluorescência (do inglês, mean fluorescence intensity - MFI; de acordo com Zhang et al., 2004) de cada grupo experimental relativa à MFI do grupo das iDC (MFI = MFIgrupo / MFIiDC); o programa utilizado foi o FlowJo (versão 7.2.5; Three Star).

A análise em citometria de fluxo em todas as células foi realizado gate em tamanho (FSC) por granulosidade (SSC), para exclusão de células mortas e debris. Para a caracterização das CTIPD, a analise foi feita por histograma. A avaliação dos marcadores de mo-DC foi feita sob o gates: FSC por FSW para a exclusão de doublets, e dot plot CD11c por HLA-DR. As CNA foram analisadas realizando gate para CFSE para selecionar Lin T CD4+ e Lin T CD8+ e para excluir mo-DC não marcadas com CFSE. Para a verificação de 
populações positivas para FoxP3 e IL-10 ou IFN- $\gamma$, foram realizados gates: CD4 e analisadas em dot plot IL-10 por FoxP3 ou IFN- $\gamma$ por FoxP3.

Quadro 2 - Anticorpos anti-humanos utilizados para a caracterização fenotípica das CTIPD e mo-DC diferenciadas ou maturadas.

\begin{tabular}{|c|c|c|c|c|c|}
\hline \multirow[t]{2}{*}{ Moléculas } & \multirow[t]{2}{*}{ Células } & \multicolumn{3}{|c|}{ Anticorpo } & \multirow[t]{2}{*}{ Fabricante } \\
\hline & & Clone & Isotipo & Fluorocromo & \\
\hline \multicolumn{6}{|c|}{ Marcação Mesenquimal } \\
\hline CD90 & $\begin{array}{c}\text { Timócitos, células } \\
\text { progenitoras } \\
\text { hematopoiéticas da medula } \\
\text { óssea, do cordão umbilical e } \\
\text { do fígado fetal, neurônios, } \\
\text { células mesenquimais do } \\
\text { estroma }\end{array}$ & 5E10 & IgG1 & $\mathrm{PE}$ & $\mathrm{BD}, \mathrm{EUA}$ \\
\hline CD105 & células mesenquimais & A12 & IgG1 & $\mathrm{PE}$ & $\mathrm{BD}, \mathrm{EUA}$ \\
\hline CD73 & células mesenquimais & AD2 & IgG1 & $\mathrm{PE}$ & $\mathrm{BD}, \mathrm{EUA}$ \\
\hline \multicolumn{6}{|c|}{ Marcação Linhagem Hematopoiética } \\
\hline CD34 & $\begin{array}{c}\text { Precursoras de células } \\
\text { hematopoiéticas e } \\
\text { endoteliais }\end{array}$ & 581 & IgG1 & APC & $\mathrm{BD}, \mathrm{EUA}$ \\
\hline CD45 & Células hematopoiéticas & H130 & IgG1 & $\mathrm{PE}$ & BD, EUA \\
\hline \multicolumn{6}{|c|}{ Marcação para monócitos, DC precursoras, imaturas e maturas } \\
\hline BDCA-1 & $\begin{array}{c}\text { Timócitos, alguns linfócitos } \\
\text { B e principalmente células } \\
\text { dendríticas }\end{array}$ & AD5-8E7 & IgG2a & $\mathrm{PE}$ & $\begin{array}{l}\text { Miltenyi } \\
\text { Biotec, } \\
\text { Alemanha }\end{array}$ \\
\hline CD11c & $\begin{array}{l}\text { Monócitos/macrófagos, } \\
\text { granulócitos, NK }\end{array}$ & B-ly6 & IgG1 & Cy7 & $\mathrm{BD}, \mathrm{EUA}$ \\
\hline CD14 & $\begin{array}{l}\text { Monócitos, macrófagos, } \\
\text { granulócitos }\end{array}$ & M5E2 & IgG2a & Fitc & $\mathrm{BD}, \mathrm{EUA}$ \\
\hline CD40 & $\begin{array}{l}\text { linfócitos B, macrófagos, } \\
\text { células dendríticas, células } \\
\text { endoteliais. }\end{array}$ & $5 \mathrm{C} 3$ & IgG1 & Cy5 & $\mathrm{BD}, \mathrm{EUA}$ \\
\hline CD80 & $\begin{array}{c}\text { linfócitos B, células } \\
\text { dendríticas e macrófagos } \\
\text { ativados }\end{array}$ & L307.4 & IgG1 & Cy5 & $\mathrm{BD}, \mathrm{EUA}$ \\
\hline CD83 & $\begin{array}{c}\text { linfócitos B do centro } \\
\text { germinativo, células } \\
\text { dendríticas e de Langerhans }\end{array}$ & HB15e & IgG1 & APC & $\mathrm{BD}, \mathrm{EUA}$ \\
\hline
\end{tabular}




\begin{tabular}{|c|c|c|c|c|c|}
\hline CD86 & $\begin{array}{c}\text { linfócitos B, monócitos, } \\
\text { células dendríticas e alguns } \\
\text { linfócitos T }\end{array}$ & $\begin{array}{c}2331 \\
(\mathrm{FUN}-1)\end{array}$ & IgG1 & Fitc & BD, EUA \\
\hline HLA-DR & $\begin{array}{l}\text { linfócitos B, monócitos, } \\
\text { macrófagos, células } \\
\text { dendríticas }\end{array}$ & $\begin{array}{c}\mathrm{L} 243 \\
(\mathrm{G} 46-6)\end{array}$ & IgG2a & Horizon & BD, EUA \\
\hline \multicolumn{6}{|c|}{ Marcação para linfócitos } \\
\hline CD4 & $\begin{array}{c}\text { Lin T, timócitos, monócitos } \\
\text { e macrófagos }\end{array}$ & RPA-T4 & 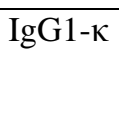 & APC, PE & $\mathrm{BD}, \mathrm{EUA}$ \\
\hline CD8 & Lin T e timócitos & SK1 & IgG1-א & APC, PE & $\mathrm{BD}, \mathrm{EUA}$ \\
\hline FoxP3 & Lin T reguladores & 150D & 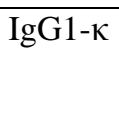 & Alex 488 & $\begin{array}{l}\text { Biolegend, } \\
\text { EUA }\end{array}$ \\
\hline \multicolumn{6}{|l|}{ IL-10 } \\
\hline IFN- $\gamma$ & & & & & \\
\hline
\end{tabular}

Fonte: Abbas et al., 2008.

\subsubsection{Mensuração de fatores solúveis das coculturas de CTIPD:DC e DC:Lin T}

Os sobrenadantes de todas as coculturas (CTIPD:DC e DC:Lin T) foram armazenados a $-70^{\circ} \mathrm{C}$ (freezer $-70{ }^{\circ} \mathrm{C}$; Revco, EUA). Para a análise de fatores solúveis os sobrenadantes foram descongelados, marcados e analisados pela técnica Cytometric Bead Array (CBA) de acordo com as instruções do kit Human Th1/Th2/Th17 Kit (BD Biosciences, EUA). Os fatores analisados foram IL-2, IL-4, IL-6, IL-10, TNF, IFN- $\gamma$ e IL-17a. As analises foram feitas por citometria de fluxo.

\subsubsection{Análise estatística}

A análise estatística para os experimento de cocultivo entre CTIPD:DC foi realizada pela multicomparação utilizando o teste Kruskall-Wallis e o teste de Dunn como pós-teste. Para os experimentos funcionais das DC sobre Lin $\mathrm{T}$, para a verificação de Lin $\mathrm{T}$ CD4+FoxP3+IL-10 e Lin T CD4+FoxP3+IFN- $\gamma$ e a análise dos fatores solúveis foi utilizado o test $\mathrm{T}$ para comparações entre duas médias de interesse. As diferenças foram consideradas significantes quanto ao valor $\mathrm{p}\left(* \mathrm{p} \leq 0,05, * * \mathrm{p} \leq 0,01 \mathrm{e}^{* * *} \mathrm{p} \leq 0,001\right)$ para análise bicaudal. Os gráficos e análises estatística foram gerados utilizando o software GraphPad Prisma (versão 5; GraphPad Software, Inc., EUA). 


\section{RESULTADOS}

\subsection{Células-Tronco Imaturas de Polpa Dentária e sua caracterização}

No Laboratório de Pesquisa Básica da Dra. Márcia M. Marques, estabelecemos uma linhagem de CTIPD, a partir do processamento de polpa dentária decídua humana. Após o processamento da polpa dentária, as CTIPD obtidas foram criopreservadas para utilização em experimentos posteriores.

As CTIPD foram inicialmente caracterizadas em relação a sua pluripotência avaliando sua capacidade em diferenciar para células tecido específico funcionais. Utilizando agentes indutores as CTIPD foram capazes de diferenciarem em células do tecido ósseo, mostrando a capacidade de deposição de cálcio avaliada pela coloração de Vermelho de Alizarina; e de diferenciarem pelo pela indução em células do tecido adipogênico, mostrando a capacidade de deposição de acumulo de vesículas de gordura avaliada pela coloração Oil Red-O (Figura 1).

As CTIPD foram caracterizadas fenotipicamente, e apresentaram marcações positivas para moléculas mesenquimais como CD73, CD90 e CD105 e não apresentaram marcação para moléculas da linhagem hematopoiéticas: CD34 e CD45 (Figura 2). Também verificamos quanto à presença das moléculas relacionadas às células da linhagem mielóide e DC diferenciadas ou maturadas mostrando que as CTIPD não apresentam marcação para BDCA1, CD11c, CD14, CD40, CD80, CD83 e CD86. Ao mesmo tempo, verificamos que as CTIPD não expressaram MHC de classe II (HLA-DR; Figura 2).

Como o cocultivo celular foi realizado em meio específico para diferenciação de monócitos em iDC (utilizando IL-4 e GM-CSF como suplemento) ou para maturação para mDC (utilizando LPS como agente ativador), visando verificar se este ambiente de cultivo poderia influenciar na fenotipagem das CTIPD. A analise dos marcadores citados acima mostrou que as CTIPD continuaram apresentando fenotipagem característica de CTA, não apresentando marcação para a linhagem mieloide e não apresentando marcação para HLA-DR (Figura 3).

Verificamos o perfil das CTIPD para expressão de moléculas de superfície para marcadores de monócitos e mo-DC imaturas e maturas. As CTIPD não apresentaram marcação para BDCA-1, CD11c, CD14, CD40, CD80, CD83 e CD86. Ao mesmo tempo, verificamos que as CTIPD não expressaram MHC de classe II (HLA-DR; Figura 1). Por esse motivo esta molécula foi escolhida para realizarmos o gate para análise da população de DC positiva para HLA-DR. Assim, excluímos as CTIPD da análise das DC (como será abordado 
no tópico a seguir). Esses resultados mostraram que as CTIPD não se diferenciaram para células da linhagem mielóide e que não são imunogênicas.

Como as CTIPD foram cocultivadas com monócitos derivados de PBMC em meio para diferenciação para DC (R10 suplementado com IL-4 e GM-CFS) e ativação por LPS, cultivamos as CTIPD nessas condições e para a verificação da provável diferenciação para células da linhagem mielóide. Após sete dias de cultivo, as CTIPD não apresentaram expressão para nenhum dos marcadores citados acima, mantendo negativa inclusive para HLA-DR (dados não mostrados).

Figura 1 - Caracterização das CTIPD.

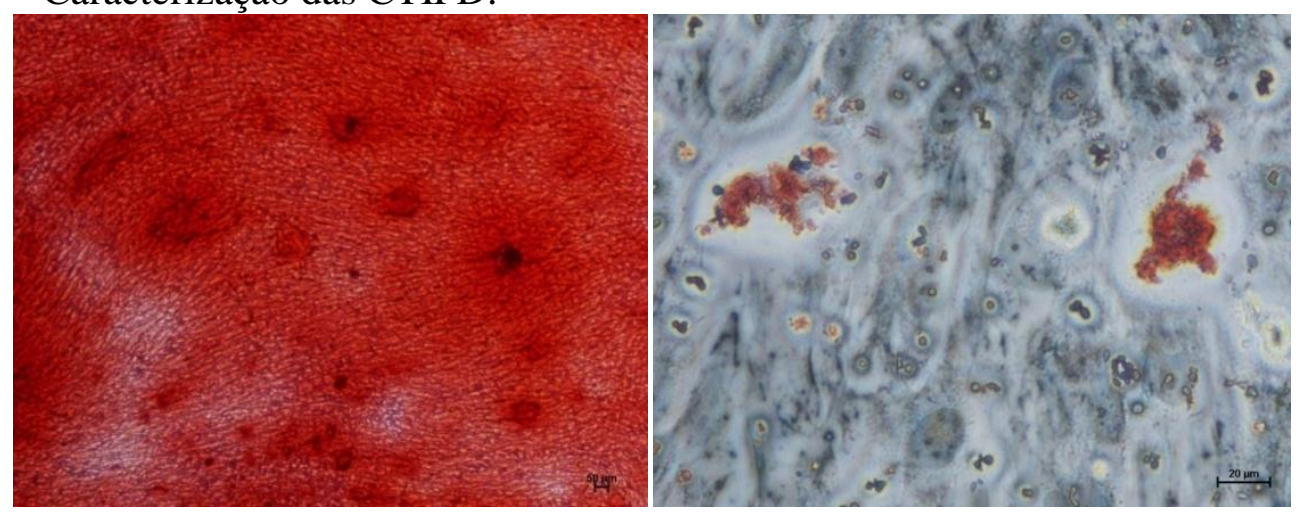

CTIPD apresentaram diferenciação osteogênica confirmada pela coloração por vermelho de Alizarina (esquerda) e apresentaram diferenciação adipogênica confirmada pela coloração com Oil Red-O (direita). 
Figura 2 - Caracterização das CTIPD por citometria de fluxo.

A

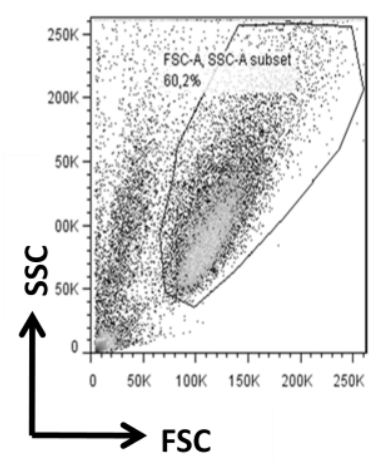

$\mathrm{C}$
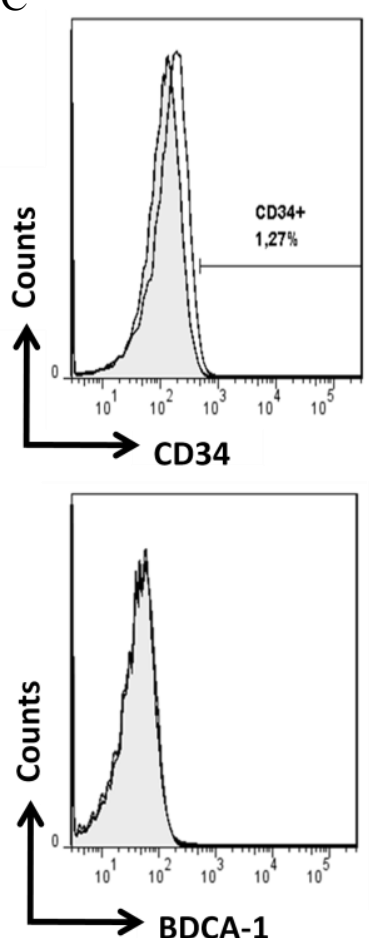

BDCA-1
B
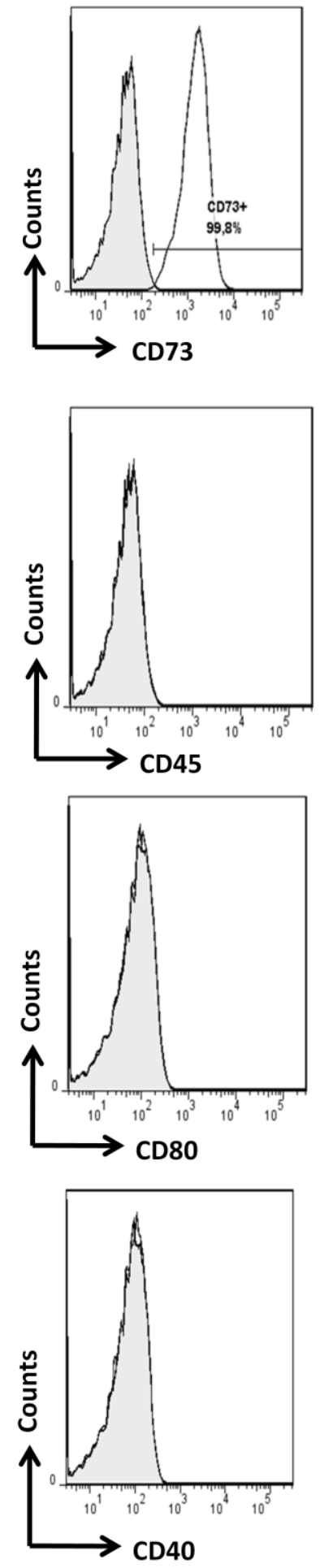
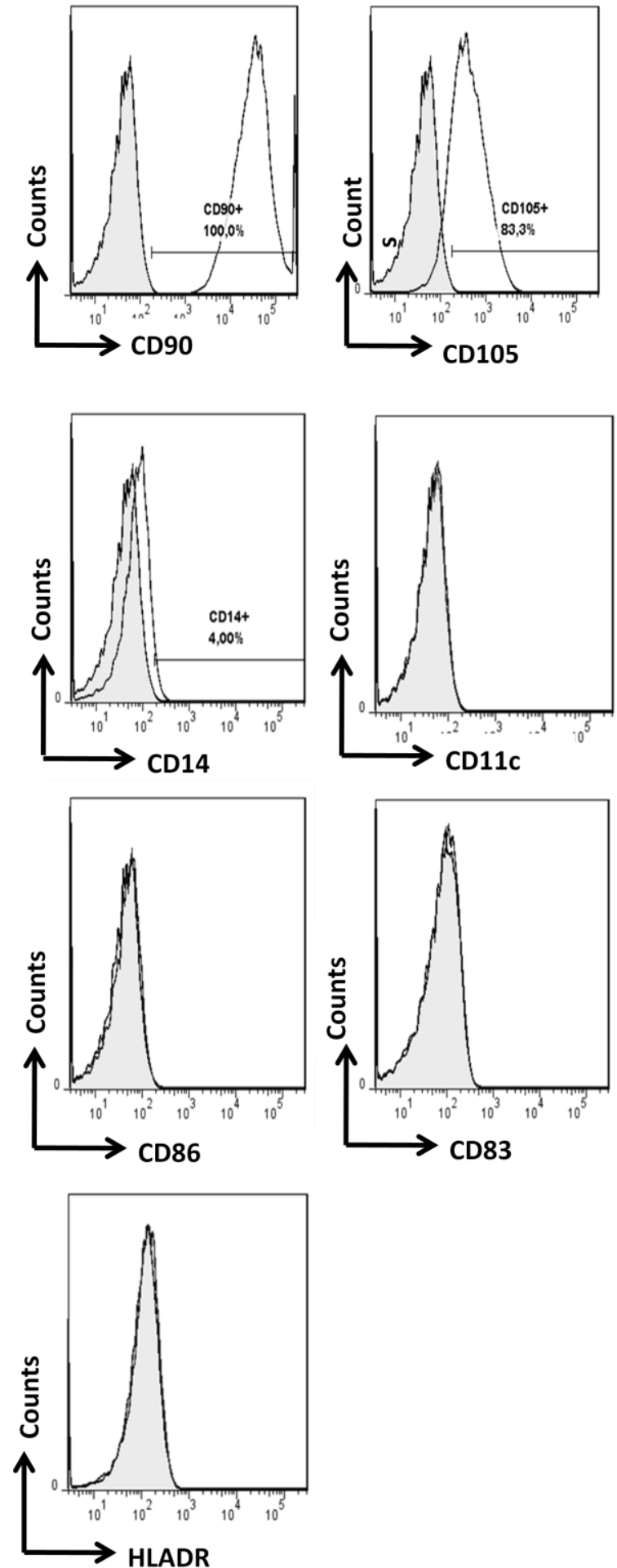

A) as células foram analisadas dentro do gate em tamanho por granulosidade. B) as CTIPD apresentaram positividade para os marcadores mesenquimais; C) e foram negativas para os marcadores para células hematopoiéticas e não apresentaram positividade para marcadores de mo-DC ou qualquer indicação para linhagem mielóide. Foram avaliados 10.000 eventos. Curva preenchida representa o grupo experimental; curva não preenchida representa o grupo controle. 
Figura 3 - CTIPD cultivadas em meio para diferenciação e maturação de DC.

A

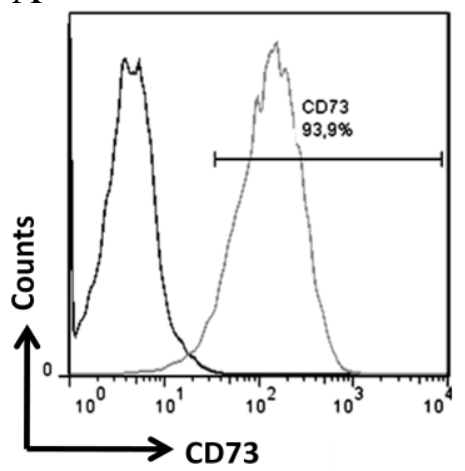

$\mathrm{B}$
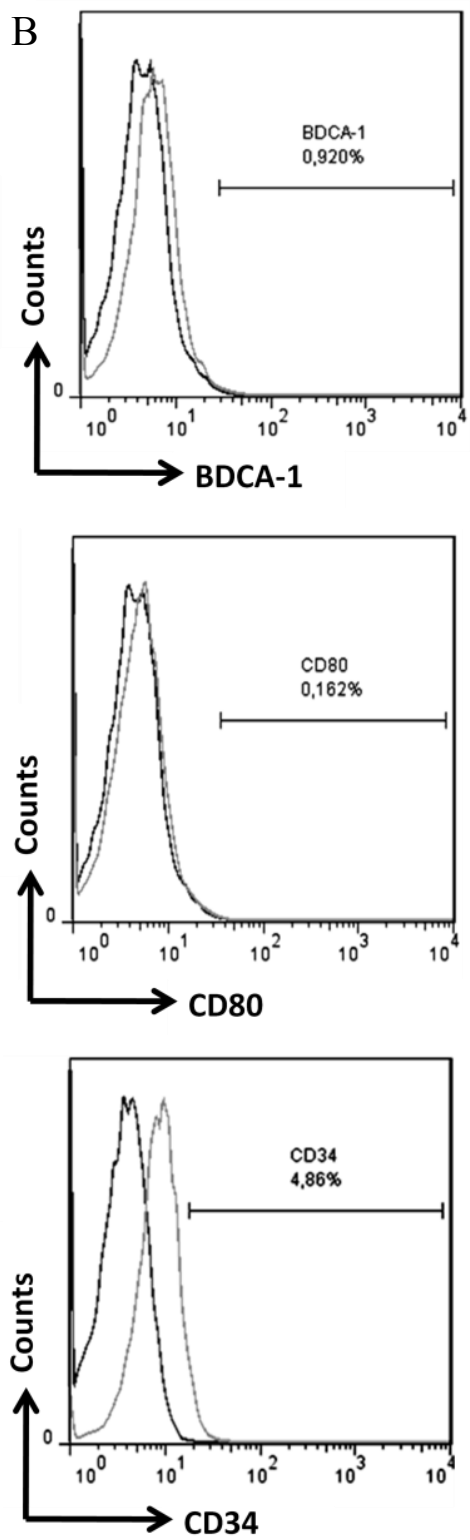
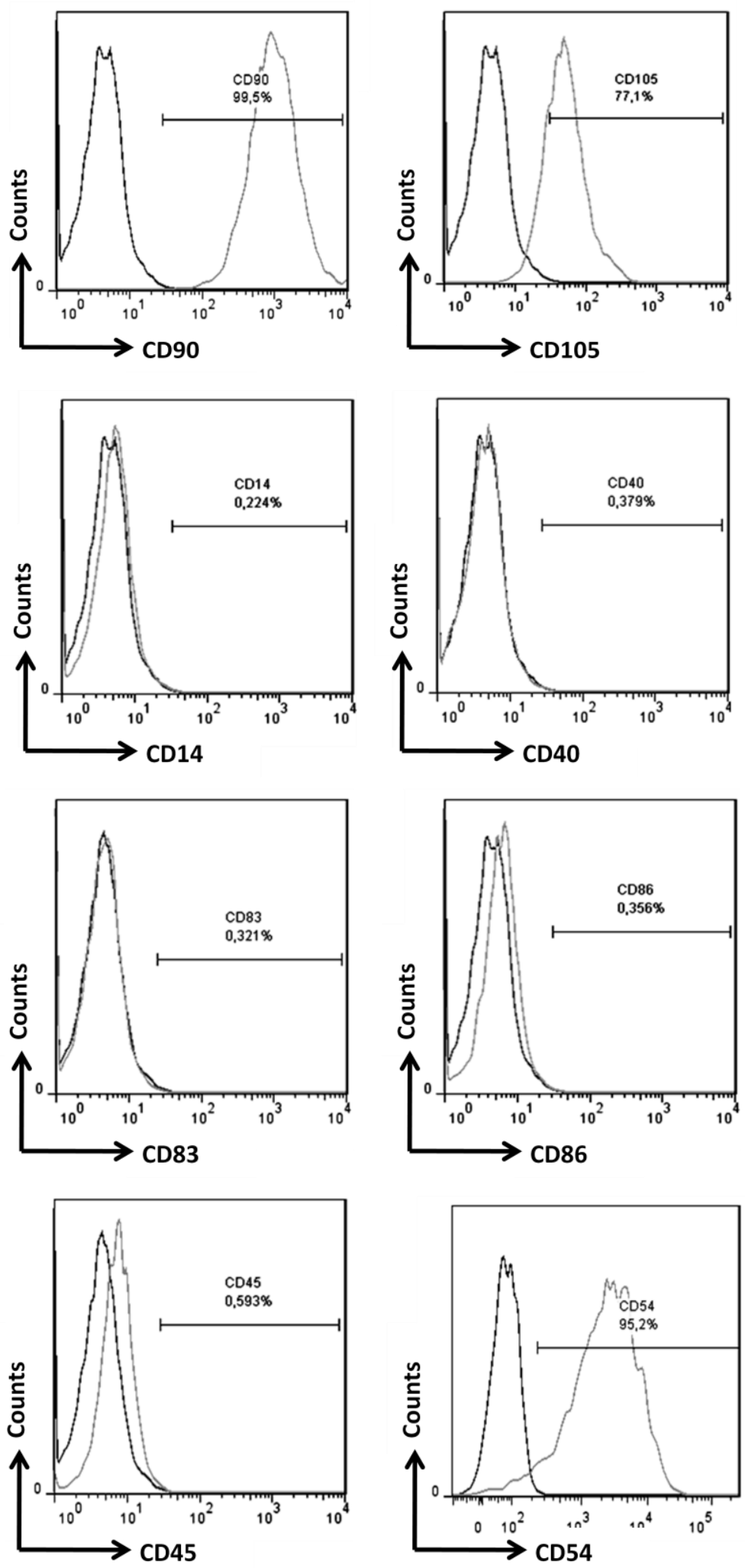

A) as CTIPD apresentaram positividade para os marcadores mesenquimais; C) e foram negativas para os marcadores para células hematopoiéticas e não apresentaram positividade para marcadores de mo-DC ou qualquer indicação para linhagem mielóide. Foram avaliados 10.000 eventos. Curva de contorno cinza representa o grupo experimental; curva de contorno preto representa o grupo controle. 


\subsection{Isolamento das populações de células mononucleares de sangue periférico}

A cocultura com as CTIPD mostraram alterações na MFI das moléculas marcadas em DC. Analisando inicialmente a diferenciação dos monócitos para iDC na presença das CTIPD, verificou-se a diminuição da expressão de moléculas ligadas a diferenciação. Tal efeito foi dependente da concentração de CTIPD e do tempo em cocultura, sendo maior na proporção de 1:10 e nos grupos que receberam CTIPD desde o dia zero em comparação com as proporções de 1:20 e 1:100, não mostrando mudanças significativas quando as CTIPD foram semeadas após cinco dias de cultivo. A adição das CTIPD após cinco dias de cultivo foi feita para coincidir a adição de LPS para a maturação neste período, e serviu para verificar se a diferenciação poderia afetar a maturação induzida por LPS. Todos os grupos, sejam iDC ou mDC, foram comparados com o MFI das iDC não cocultivadas com CTIPD (iDC s/CTIPD). Dessa forma, analisando os grupos iDC na proporção de 1:10 no cocultivo desde o dia zero de cultivo, a comprovação da atenuação da diferenciação foi mais evidente para o marcador BDCA-1 que teve uma diminuição de $70 \%$ no MFI ( $\mathrm{p} \leq 0,01$; Figura 4). A molécula CD11c também sofreu uma diminuição de sua expressão pela metade, apesar da diferença não ser significativa. Já o marcador CD14 apresentou aumento em duas vezes em sua expressão $(\mathrm{p} \leq 0,01)$. A diminuição de CD11c e o aumento CD14 podem indicar que ao mesmo tempo em que é observada a diminuição da diferenciação para iDC (caracterizadas pela presença de marcadores BDCA-1 e CD11c) é observado a permanência de mais células indiferenciadas (caracterizada pela expressão de CD14) em cocultura. Outros marcadores que indicam maturação (Quadro 2) de mDC não apresentaram mudanças significativas na intensidade dos marcadores, uma vez que, analisamos aqui apenas os grupos de iDC, que não foram ativadas com LPS. A intensidade do marcador HLA-DR também não foi alterada (Figura 4). 
Figura 4 - Análise da imunomodulação promovida pelas CTIPD sobre as iDC.
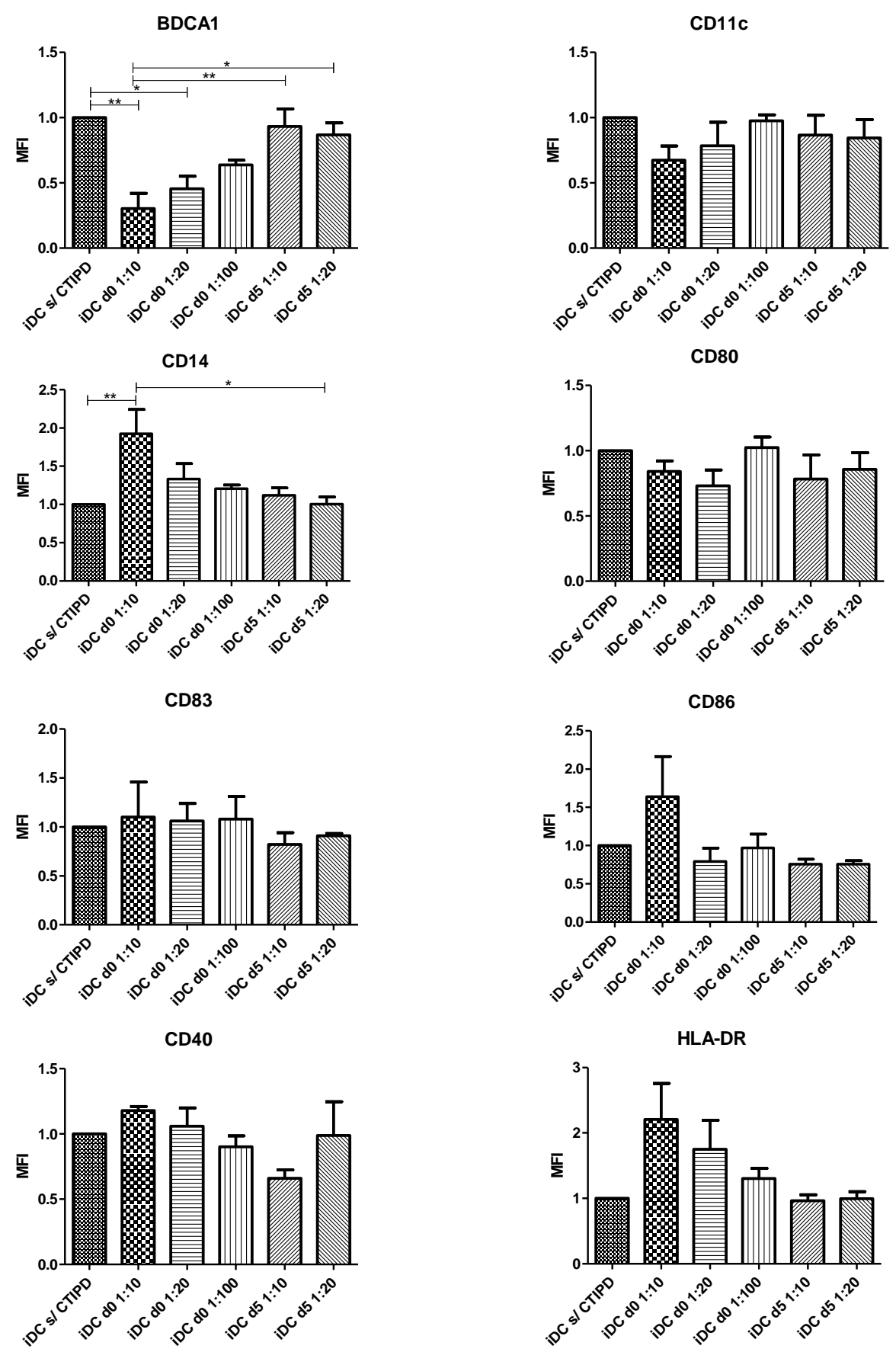

Os gráficos mostram a expressão (em MFI) das moléculas, presentes em mo-DC, que indicam diferenciação e maturação celular. iDC - mo-DC imaturas e diferenciadas; MFI - média de fluorescência; d0 - iDC cocultivadas com CTIPD desde o dia zero; d5 - iDC cocultivadas com CTIPD depois de cinco dias de cultivo; * $\mathrm{p} \leq 0,05 ; \mathrm{e} * *$ $\mathrm{p} \leq 0,01$, teste Kruskall-Wallis e pós-teste Dunn. 
No experimento onde as células foram induzidas a maturar pela adição de LPS ao meio, verificou-se que a maturação das $\mathrm{mDC}$ foi alterada, avaliando a MFI dos marcadores, com maior evidência nos grupos 1:10 (CTIPD:mDC), onde o cocultivo foi realizado desde o dia zero. Dessa forma, pode-se verificar a diminuição da expressão das moléculas CD40 em $50 \%$ ( $\mathrm{p} \leq 0,01)$, e a diminuição da expressão dos marcadores em 35\% para CD80, 67,4\% para CD83 e 50\% para CD86, mesmo não havendo diferença significativa, indicando que as CTIPD atenuaram a ativação ou maturação de iDC para mDC (Figura 5).

Os grupos que receberam CTIPD no mesmo dia da adição do LPS, ou seja, após cinco dias de cultivo, não tiveram a expressão de suas moléculas alteradas significativamente. Isso indica que as $\mathrm{mDC}$ foram imunomoduladas pelas CTIPD ainda no período de diferenciação de monócitos para iDC (Figuras 4 e 5). Esse resultado é reforçado ao fato de que, mesmo após a maturação das DC a expressão de BDCA-1 $(\mathrm{p} \leq 0,05)$ e CD11c continuaram baixas, e a de CD14 (mesmo não mostrando diferença significativa) continuou aumentada. A expressão de HLA-DR não apresentou diferença significativa em nenhum dos grupos testados. Dessa forma, esta molécula foi escolhida para realizar o gate para população positiva para HLA-DR uma vez que a população de CTIPD não apresentava tal marcação ao longo do experimento. Assim excluímos as CTIPD da análise das mo-DC em citometria de fluxo e para a separação das mo-DC para o coculutivo com Lin T. 
Figura 5 - Análise da imunomodulação promovida pelas CTIPD sobre as mDC.

BDCA1

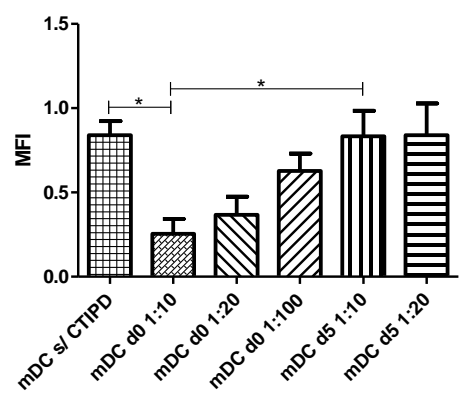

CD14

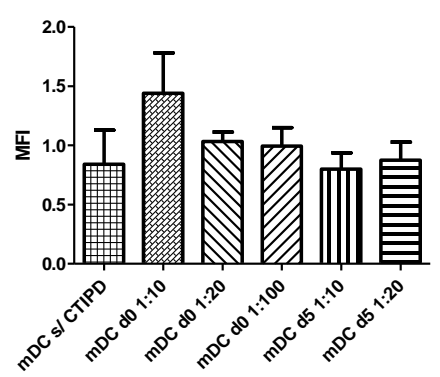

CD83

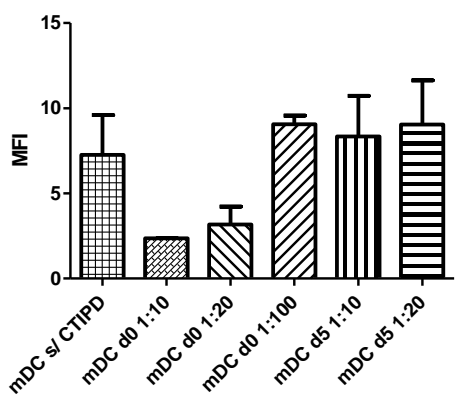

CD40

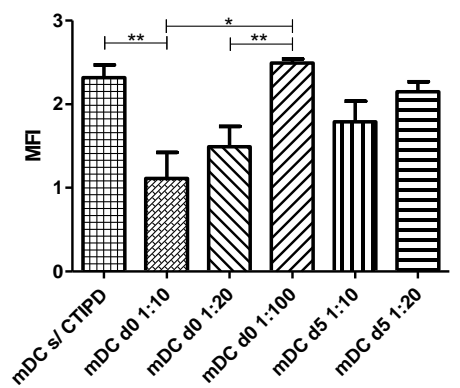

CD11c
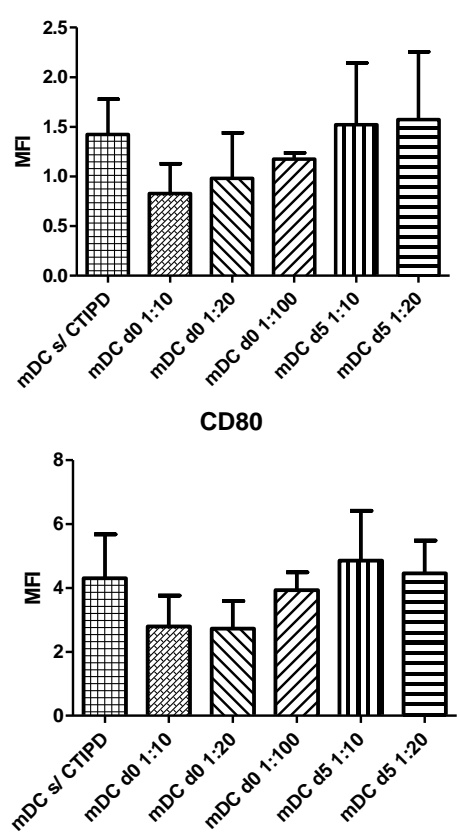

CD86

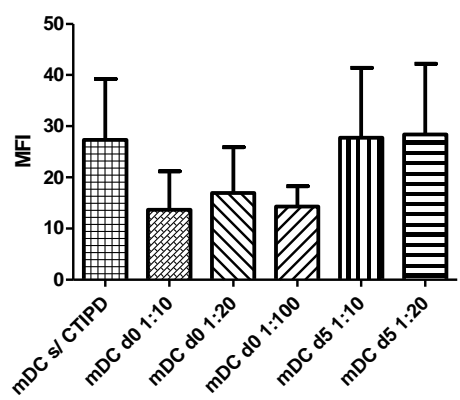

HLA-DR

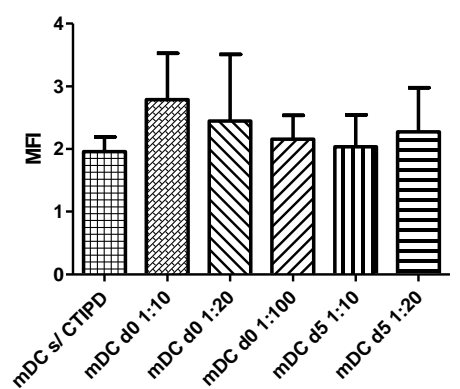

Os gráficos mostram a expressão (em MFI) das moléculas, presentes em mo-DC, que indicam diferenciação e maturação celular. $\mathrm{mDC}$ - mo-DC maturas; MFI - média de fluorescência; $\mathrm{d} 0$ - mDC cocultivadas com CTIPD desde o dia zero; $\mathrm{d} 5$ - mDC cocultivadas com CTIPD depois de cinco dias de cultivo; ${ }^{*} \mathrm{p} \leq 0,05$; e ${ }^{* *} \mathrm{p} \leq 0,01$, teste Kruskall-Wallis e pós-teste Dunn. 


\subsection{Funcional das DC cultivadas com CTIPD: ensaio de proliferação de linfócitos T}

Uma vez que as mo-DC foram imunomoduladas na presença das CTIPD, pretendeu-se com o ensaio de proliferação de linfócitos, verificar sua funcionalidade.

Após o cocultura das mo-DC com CTIPD, foi verificado que os grupos iDC e mDC que receberam CTIPD desde o dia zero, na proporção de 1:10 (Tabela 1) apresentaram os resultados mais expressivos. Dessa forma, utilizamos esses grupos para condicionar as moDC para posterior cocultivo com linfócitos derivados de CNA de PBMC.

As mo-DC (HLA-DR+) condicionadas na presença das CTIPD (HLA-DR-) foram isoladas das CTIPD por beads magnéticas. A separação apresentou o rendimento de 92,3\% para a marcação de CD45 (Figura 6).

As CNA representam uma população de células compostas principalmente por Linfócitos. O ensaio de proliferação tem por objetivo verificar se Lin T CD4+ (auxiliares) e Lin T CD8+ (citotóxicas) proliferam pela ativação induzida pelas mo-DC como células apresentadoras de antígenos (APC).

Figura 6 - Rendimento das mo-DC purificadas por beads magnéticas após a cocultura com CTIPD.

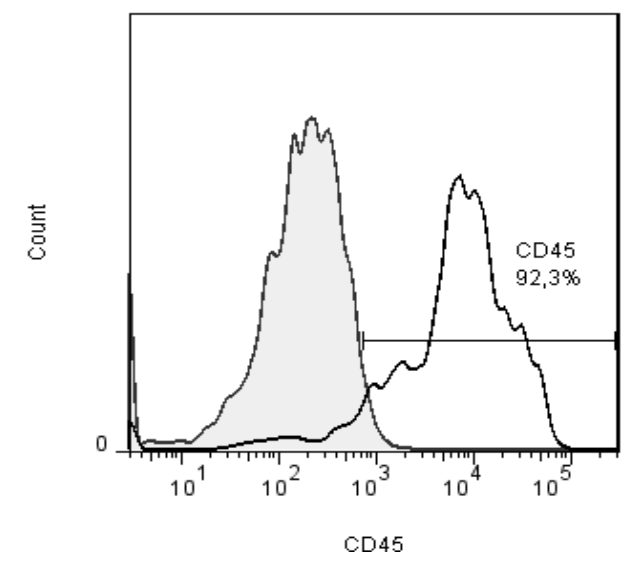

Foi realizado o gate em tamanho por granulosidade e o rendimento foi avaliado para células positivas para CD45.

Neste experimento as mo-DC foram ativadas ou não com LPS, em um pré-cultivo, e a ativação de Lin $\mathrm{T}$ ocorreu pelas próprias mo-DC, no cocultivo posterior. O cocultivo promoveu o aumento da proliferação de Lin T CD4+ e de Lin T CD8+, sendo o aumento ainda maior quando o cocultivo foi com mDC (Figura 7). 
Em seguida foi verificada se as mo-DC condicionadas com CTIPD tiveram sua capacidade de estimular linfócitos reduzido. A taxa de proliferação dos Lin T CD4+, na presença de iDC anteriormente cocultivas com CTIPD (iDC[CTIPD]), diminuiu $63 \% \mathrm{em}$ relação ao iDC não cocultivas com CTIPD ( $\mathrm{p} \leq 0,01$, Figura 7 ). $\mathrm{mDC}$ pré-cultivadas com CTIPD (mDC[CTIPD]) levou à diminuição em 50\% da taxa de proliferação de Lin T CD4+ em relação às $\mathrm{mDC}$ sem contato com CTIPD $(\mathrm{p} \leq 0,05)$. Da mesma forma, a proliferação de Lin T CD8+ foi diminuída em 40\% $(\mathrm{p} \leq 0,05)$ e em $26 \%$ (não apresentou diferença significativa) em cocultura com iDC[CTIPD] e mDC[CTIPD], respectivamente (Figura 7).

Figura 7 - Análise Funcional das mo-DC [CTIPD] sobre a proliferação de Lin T.
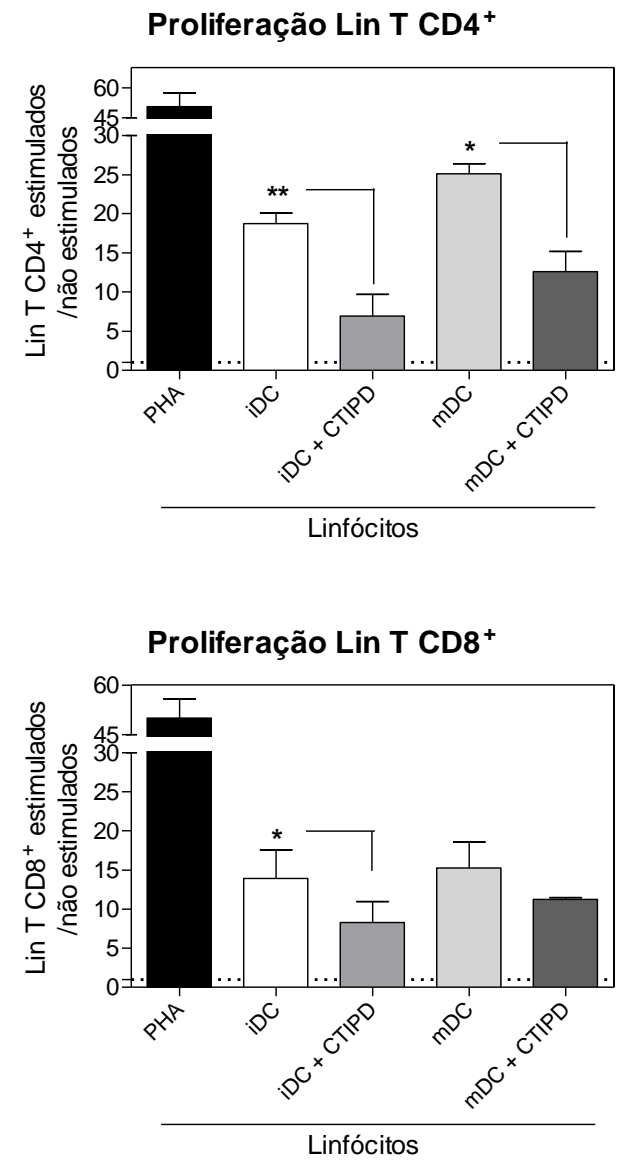

mo-DC foram separadas das CTIPD por beads magnéticas e cocultivadas com $1 \times 10^{5}$ CNA (previamente marcadas com CFSE), na razão 1:10. Após 5 dias, CNA foram marcadas para CD4 e CD8, e a diluição CFSE foi verificada pela análise de citometria de fluxo, para determinar o perfil de proliferação celular. Para esta análise foi realizado gate para FSC e SSC, e gate para Lin T positivos para CD4 ou CD8. Estes dados são um valor relativo entre a taxa de proliferação (\%) da população dos grupos experimentais divididas pela taxa de proliferação (\%) da população do grupo controle (que não receberam qualquer estímulo proliferativo). PHA foi utilizado como um estímulo policlonal-positivo. 20.000 eventos foram adquiridas. Linhas tracejadas representam a proliferação da população do grupo controle. ${ }^{*} \mathrm{p} \leq 0,05 ;{ }^{* *} \mathrm{p} \leq 0,01$, test T. 


\subsection{Avaliação da população Lin T CD4+FoxP3+ e citocinas intracelular IL-10 e IFN- $\gamma$}

Uma vez que as mo-DC mostraram a propriedade em diminuir a proliferação de Lin T, o próximo passo foi verificar se a população de Lin CD4+ que teve sua proliferação diminuída pelas mDC[CTIPD] apresentou aumento na proporção de Lin T FoxP3+. Em paralelo, foi verificado se essa população FoxP3+ apresentava marcação para as citocinas IL10 e IFN- $\gamma$.

O cocultivo de Lin $\mathrm{T}$ com $\mathrm{mDC}[\mathrm{CTIPD}]$ mostrou aumento da proporção de CD4+FoxP3+ aproximadamente em três vezes $(\mathrm{p} \leq 0,01)$ em relação ao cocultivo com Lin $\mathrm{T}$ com mDC. Destas, a população que apresentou marcação para IL-10, ou seja, Lin T CD4+FoxP3+IL-10+ também teve sua proporção aumentada em relação ao grupo de Lin T cocultivados apenas com mDC (Figura 8). Da mesma forma, verificamos que a população de Lin T CD4+Foxp3+ também apresentaram marcação para IFN- $\gamma$ (Lin T CD4+FoxP3+IFN- $\gamma+$; Figura 9). 
Figura 8 - Análise de Lin T CD4+ quanto a marcação para FoxP3, IL-10 e IFN- $\gamma$.

A
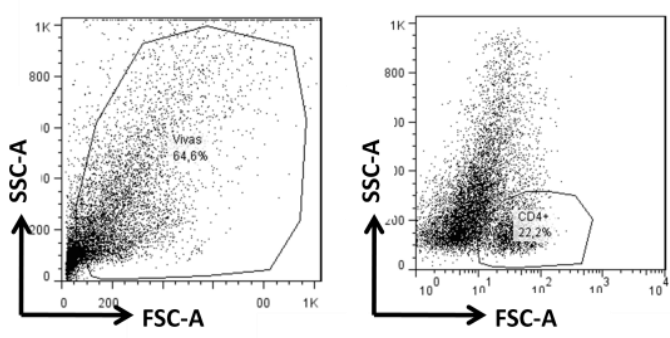

$\mathrm{B}$
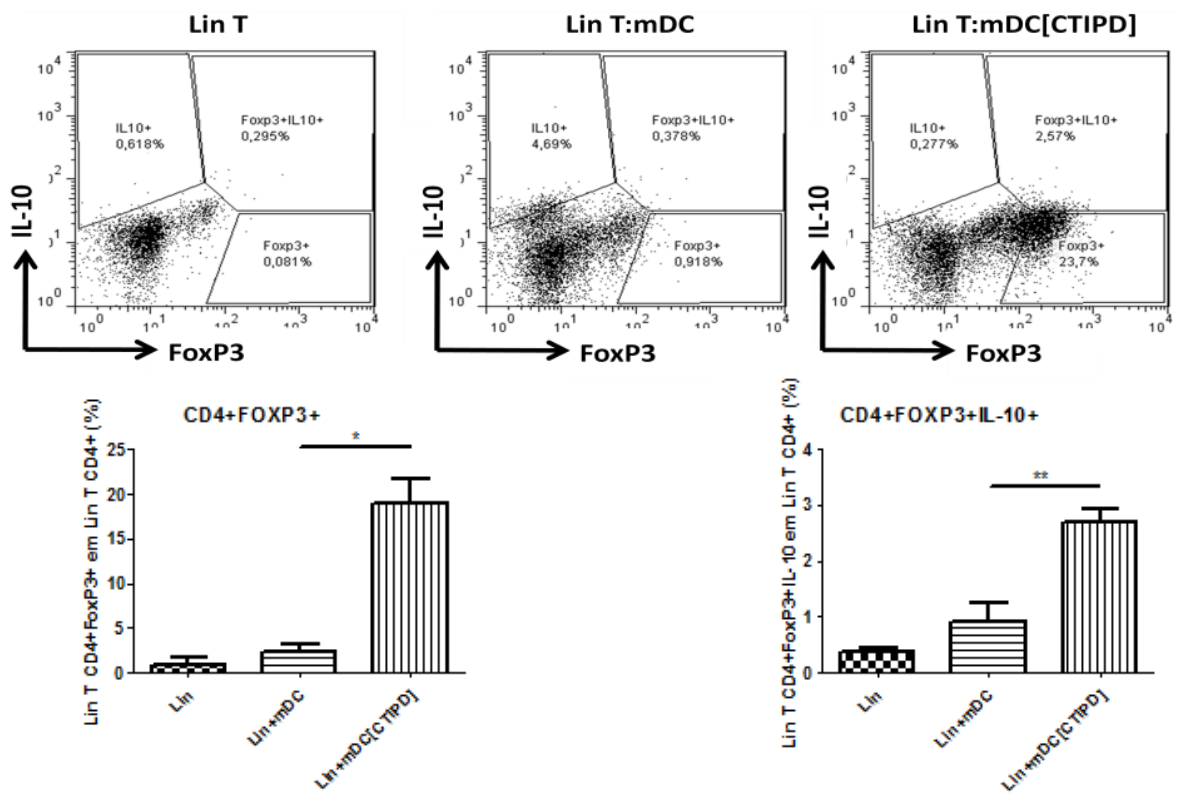

$\mathrm{C}$
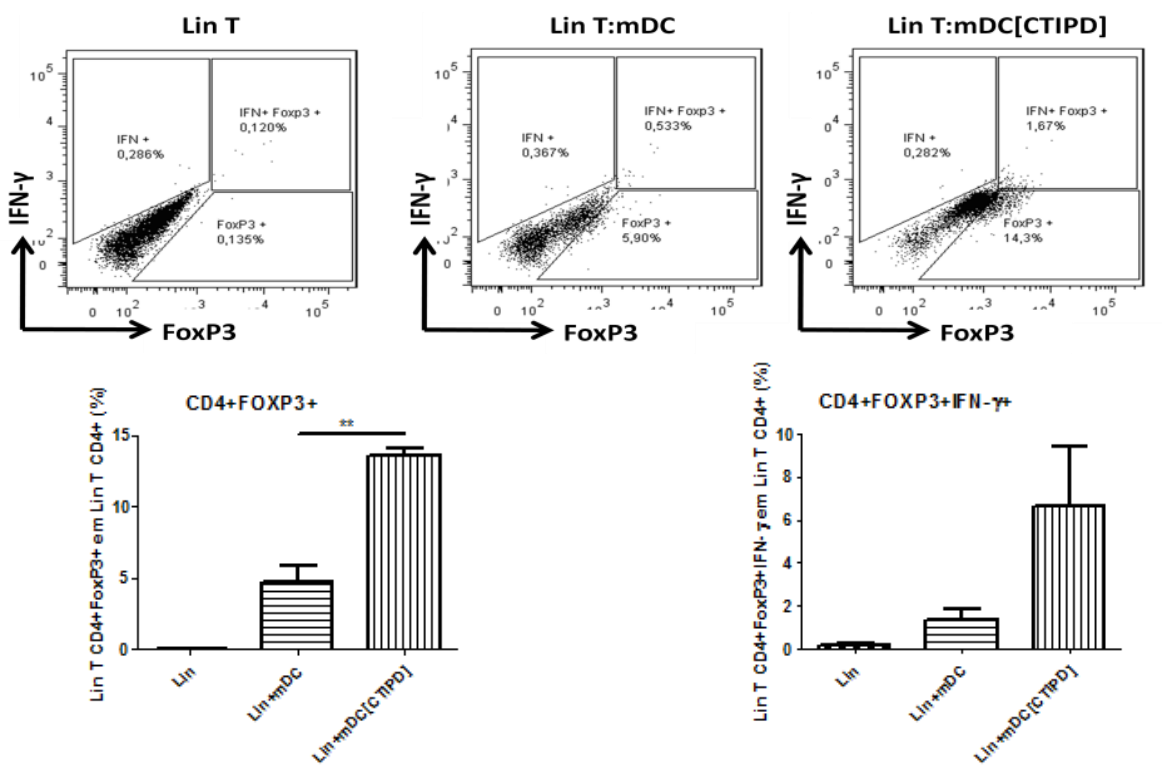

A) gate tamanho por granulosidade (direita) e gate em células CD4+ (esquerda). Lin T foram cocultivados com $\mathrm{mDC}[\mathrm{CTID}]$ e verificado a proporção de células CD4+ positivas para FoxP3. B e C) gráficos representativos das análises em citometria de fluxo e gráficos em colunas mostrando a média de $\mathrm{n}=4$ da proporção de população de Lin T CD4+FoxP3+ e Lin T CD4+FoxP3+IL-10+ (B) e da proporção de população de Lin T CD4+FoxP3+ e Lin T CD4+FoxP3+IL-10+ (C). Foi aplicado o teste $T$ entre os grupos Lin+mDC e Lin+mDC[CTIDP]; *p $\leq 0,05$; ** $\mathrm{p} \leq 0,01$, test $\mathrm{T}$. 


\subsection{Análise de fatores solúveis por CBA}

Nem todos os resultados apresentaram diferenças significativas para $n=4$ (Figura 9 e 10), porém, estão em acordo com a literatura. A análise dos fatores solúveis para a cocultura das CTIPD:mo-DC mostrou que não houve diferença nos níveis de IL-2 no experimento com iDC. Quando as mo-DC foram estimuladas com LPS houve aumento nos níveis de IL-2, mas foram diminuídos (59\%) na presença das CTIPD. IL-6 apresentou-se a níveis basais na cultura de iDC, mas na presença das CTIPD os níveis aumentaram significativamente $(\mathrm{p} \leq 0,05)$. Os níveis chegaram ao mesmo patamar na cultura das $\mathrm{mDC}$ com ou sem CTIPD. TNF- $\alpha$ e IFN- $\gamma$ apresentaram níveis muito baixos ou indetectáveis nas culturas de iDC com ou sem a presença de CTIPD. No entanto, na presença de LPS houve a secreção desses fatores pelas $\mathrm{mDC}$, os quais foram diminuídos na presença de CTIPD, em 73\% para TNF- $\alpha$ e 79\% para IFN- $\gamma(\mathrm{p} \leq 0,05)$. De modo semelhante, a IL-10 foi secretado apenas na cultura mDC, no caso, havendo aumento em 86\% na presença de CTIPD (Figura 9). A IL-17 não foi detectada em ambos os grupos testados; o fator IL-4 foi utilizado para diferenciar monócitos em iDC, por tanto, estava presente no sobrenadante não apresentando diferença entre os grupos (dados não mostrados). 
Figura 9 - Níveis de fatores solúveis do cocultivo entre mo-DC e CTIPD.
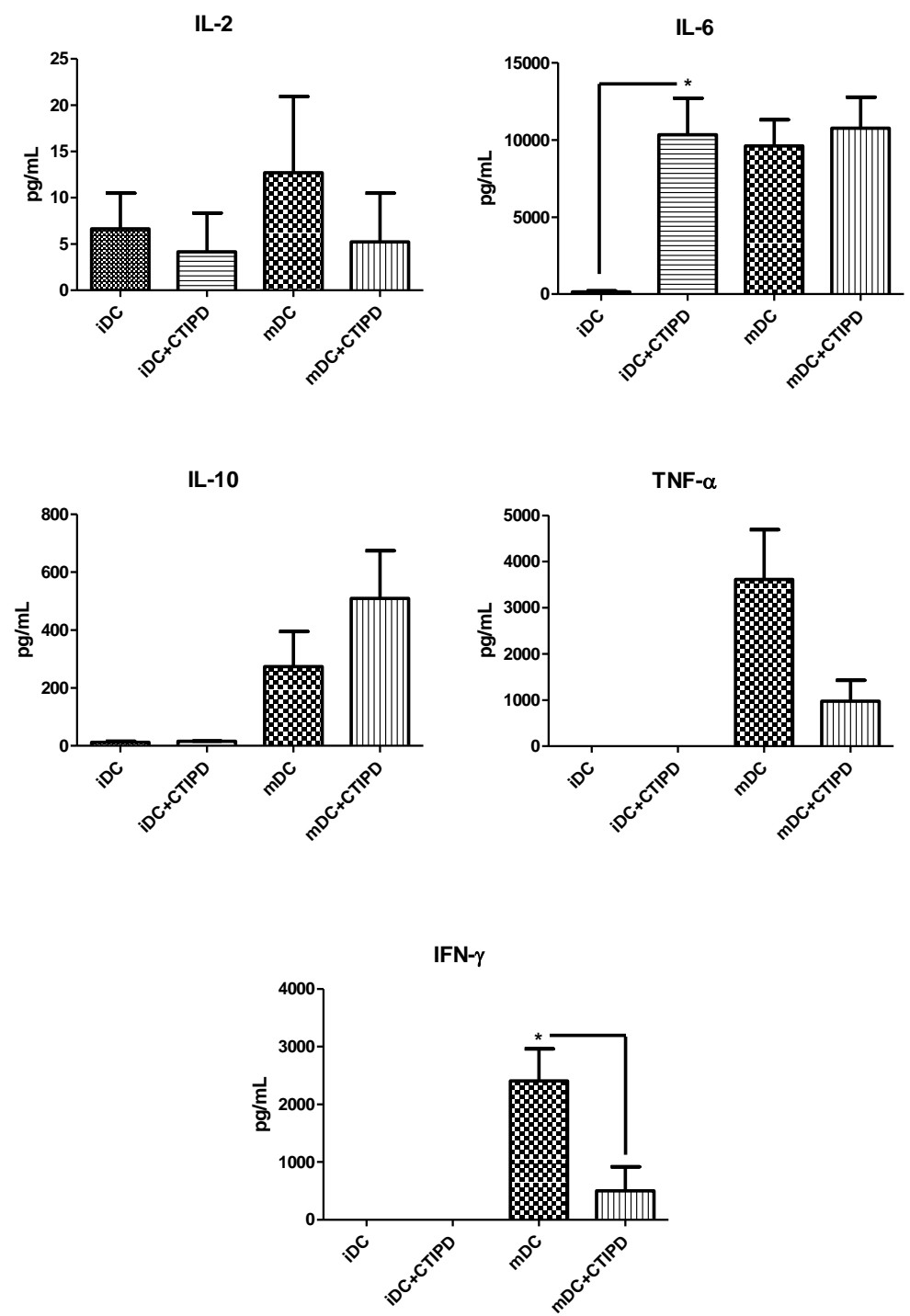

Gráficos indicam os níveis em pg/mL (detecção pela técnica CBA) dos fatores solúveis presentes na cultura de mo-DC (cocultivadas ou não com CTIPD) estimuladas ou não com LPS para maturação em mDC. As comparações foram feitas utilizando test $\mathrm{T}$ entre iDC e iDC+CTIPD e entre $\mathrm{mDC}$ e $\mathrm{mDC}+\mathrm{CTIPD} ;{ }^{*} \mathrm{p} \leq 0,05 ; * *$ $\mathrm{p} \leq 0,01$, test $\mathrm{T}$.

Os sobrenadantes do ensaio funcional das mo-DC frente aos Lin $\mathrm{T}$ também foram analisados para os fatores solúveis. Em relação às mo-DC, separadas por beads magnéticas do cocultivo com as CTIPD, mas não cocultivas com Lin T, houve apenas a detecção de IL-4, porem não houve diferença nos níveis entre os grupos (Figura 10). Vale esclarecer que nos cinco dias de cocultivo entre Lin T e mo-DC não foi utilizado IL-4 e GM-CSF recombinantes, uma vez que monócitos do PBMC já haviam sofrido diferenciação sete dias antes do cocultivo com Lin T. Desse modo, verifica-se que IL-4 detectado teve seu nível diminuído quando Lin $\mathrm{T}$ foram cocultivados com mo-DC que foram previamente tratados com CTIPD. 
No cocultivo com Lin $\mathrm{T}$ os fatores foram imunomodulados pelas mo-DC previamente cocultivados com CTIPD. Os cultivos de Lin T na presença de iDC e mDC foi detectada a presença de IL-2, o qual foi diminuída em $41 \%$ quando Lin T foram cocultivados com iDC previamente cultivadas com CTIPD, o mesmo sendo observado para mDC[CTIPD] ocorrendo diminuição em 59\% (Figura 10). IL-6 apresentou níveis expressivos apenas nas coculturas entre Lin-T e mDC[CTIPD] ou entre Lin T e mDC, atingindo níveis equiparados ao controle positivo tratado com PHA, porem não houve diferença entre esses grupos. Para IL-10, apesar dos níveis dentro do grupo de iDC não terem tido diferença nos níveis, em $\mathrm{mDC}$ a cocultura de Lin T com mDC[CTIPD] apresentou aumento em 93\% em relação ao cocultivo apenas com mDC. TNF- $\alpha$ e IFN- $\gamma$ também apresentaram aumento apenas no grupo mDC sendo que o cocultivo mDC[CTPID] diminuiu em $23 \%$ para TNF- $\alpha$ e $46 \%$ para IFN- $\gamma$ em relação ao cocultivo apenas com mDC. O fator IL-17 não foi detectado em nenhuma das análises, apenas no grupo controle positivo que recebeu PHA. 
Figura 10 - Níveis de fatores solúveis do cocultivo entre mo-DC[CTIPD] e Lin T.

IL2

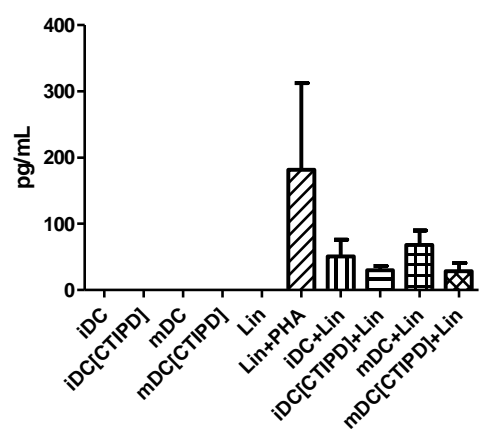

IL6

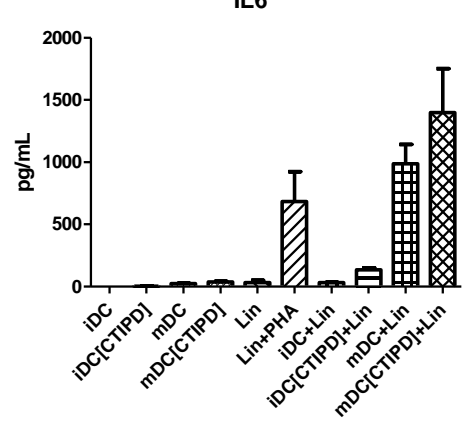

$\mathrm{TNF} \alpha$

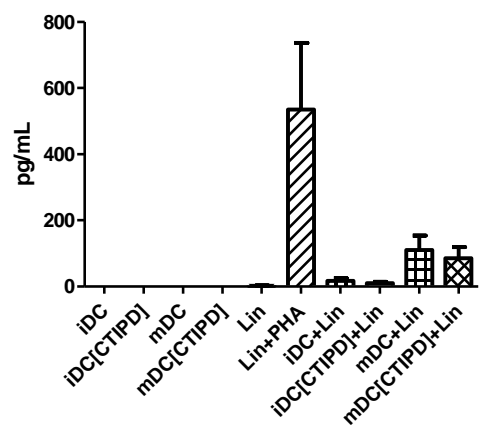

IL4

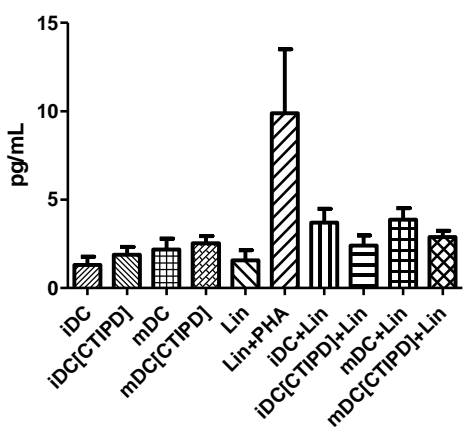

IL10

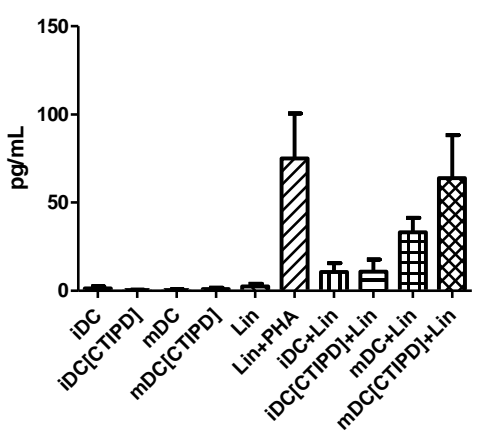

IFNg

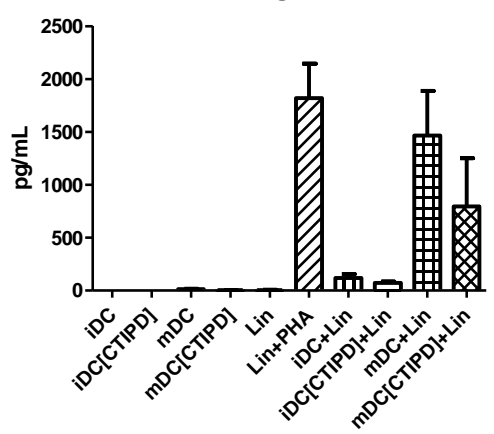

IL17

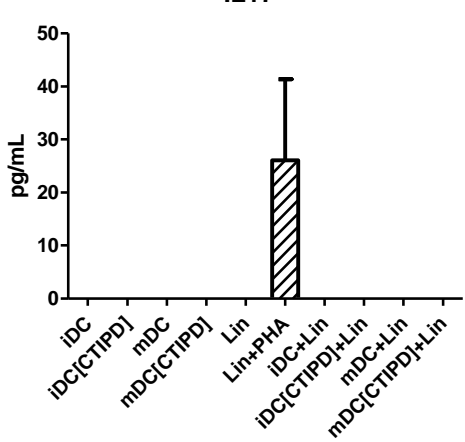

Gráficos indicam os níveis em pg/mL (detecção pela técnica CBA) dos fatores solúveis presentes na cultura de Lin T com mo-DC (cocultivadas previamente ou não com CTIPD) estimuladas ou não com LPS para maturação em mDC . As comparações foram feitas utilizando test $T$ entre iDC+Lin e iDC[CTIPD]+Lin e entre mDC+Lin e mDC[CTIPD]+Lin; os testes não mostraram diferença significativas (test $T$ ). 


\section{DISCUSSÃO}

Em 2005, Aggarwal et al. obtiveram dados in vitro que sugerem que a capacidade das CTM em inibir a IFN- $\gamma$ e aumentar a secreção de IL-4 podem orquestrar uma mudança da proeminência pró-inflamatória de células Th1 em direção ao aumento de células Th2 antiinflamatórias, bem como a regulação de vários marcadores de maturação de DC e inibição da secreção de TNF- $\alpha$. Os pesquisadores mostrando que CTM levam ao estado de tolerância imunológica, o que pode ser benéfico para muitos tratamentos, por exemplo, enxerto, doença do enxerto contra hospedeiro. Desde então, muitos trabalhos com CTM, de muitas fontes teciduais, foram realizadas em relação a imunomodulação. Como será mostrado a seguir, estes trabalhos nos guiaram a explorar a capacidade imunomoduladora de CTM de uma fonte de ainda pouco explorada, que são as CTIPD.

Apesar de alguns trabalhos terem sido publicados em relação ao efeito imunomodulador das CTM sobre DC, ninguém investigou a gama de marcadores e fatores solúveis de cocultura entre CTIPD:mo-DC e mo-DC[CTIPD]:Lin T, incluindo para interação dos tipos células iDC, mDC, Lin T CD4+ e Lin T CD8+, e presença de Lin T CD4+FoxP3+. Além do mais, recentes investigações das propriedades das CTIPD começaram a avançar e este trabalho propôs investigar o aspecto imunomodulador dessas células.

As CTM, no geral, possuem determinadas características para comprovação de sua pluripotência. As CTIPD, isoladas no presente trabalho, foram positivas para marcadores mesenquimais e negativas para marcadores hematopoiéticos. A sua pluripotência foi comprovada pela capacidade em se diferenciarem para linhagens mesenquimais, no caso a osteogênica e a adipogênica. Estas células também foram caracterizadas como negativas para os marcadores da linhagem mielóide e marcadores específicos para mo-DC, estando assim de acordo com os mesmos resultados encontrados por Choi et al. (2012), em células murinas, e de acordo com Chan et al. (2006), Le Blanc et al. (2003a) e Zhang et al. (2004) em CTM humanas. Ainda, da mesma forma como foi encontrado no presente trabalho, estes autores mostraram que CTM humanas não expressam moléculas MHC de classe II, mesmo após o cultivo em condições de diferenciação de mo-DC (meio suplementado com IL-4 e GM-CSF e estimulo com LPS), indicando que essas células não se diferenciaram para linhagens mo-DC e que não são imunogênicas. Esta característica nos permitiu utilizar o marcador HLA-DR para a separação das células após o cocultivo entre mo-DC (HLA-DR+) e CTIPD (HLA-DR-) para o ensaio funcional com Lin T (Dzionek et al., 2000, Le Blanc et al., 2003a). 
A propriedade imunomoduladora das CTIPD verifica-se logo na diferenciação de DC a partir de monócitos (mo-DC). Tal influência refletiu na maturação e na funcionalidade como APC na estimulação de Lin T. Assim, analisando a diferenciação para iDC foi verificado que as CTIPD atenuaram a expressão da molécula BDCA1 (também nomeada CD1c), marcador específico que indica a diferenciação de monócitos para DC do tipo 1, proveniente da linhagem mielóide, caracterizadas por serem CD11chigh, CD123low, CD14low, BDCA-2(Dzionek et al., 2000). Consequentemente, a expressão de CD11c foi diminuída e a expressão de CD14 foi aumentada. Isso pode indicar que, enquanto é observado a diminuição da diferenciação para iDC (diminuição da marcação para BDCA-1 e CD11c), é observado também a permanência de mais células indiferenciadas (aumento da marcação para CD14) em cocultura.

Após o estimulo com LPS, as moléculas coestimuladoras, CD80, CD83 e CD86. que têm suas expressões aumentadas quando mo-DC são maturadas (mDC), sofreram diminuição na presença das CTIPD. Este efeito ficou bem evidente em relação à molécula CD40, que, assim como as moléculas anteriores, é coestimuladora requerida para ativar Lin T (MarchalSomme et al., 2007). Nos experimentos aqui empregados, não foi possível afirmar que as CTIPD agem imunomodulando no período da maturação. No entanto, como os marcadores que indicam a diferenciação se mantiveram alterados nos experimentos com $\mathrm{mDC}$, seguindo o mesmo padrão do experimento de diferenciação, os resultados sugerem que as iDC provavelmente não estejam completamente diferenciadas, não maturando adequadamente como se vê pela diminuição dos marcadores. Outro dado que reforça essa teoria é a expressão inalterada dos marcadores (de diferenciação e de maturação) quando as CTIPD foram adicionadas na cocultura após cinco dias de cultivo, junto com o estímulo por LPS. No entanto, essa pode ser uma fraca evidência, uma vez que as CTIPD podem ter atuado, sobre as mo-DC, dependente do tempo - a imunomodulação foi mais evidente quando os dois tipos celulares foram colocados em contatos desde o cultivo celular (no dia zero). Além disso, o efeito imunomodulador das CTIPD sobre a diferenciação e maturação das mo-DC foi maior quando maior eram as quantidades de CTIPD em relação às mo-DC, mostrando que o efeito imunomodulador é dependente da concentração de CTIPD. Esses resultados sugerem que o efeito imunomodulador é dependente do tempo de exposição das mo-DC às CTIPD ou, simplesmente, porque a imunomodulação ocorreu em um estágio específico no início da diferenciação e após cinco dias de cultivo o efeito imunomodulador já não era tão determinante. O mesmo não se pode inferir em relação à maturação, pois a adição das CTIPD no mesmo período da estimulação com LPS só permitiu o contato entre as células por dois 
dias; e a imunomodulação observada na maturação para $\mathrm{mDC}$, quando o cocultivo foi realizado desde o dia zero, pode ser atribuída, como descrito acima, à imunomodulação ocorrida no período da diferenciação. Para a elucidação dessas hipóteses, a sugestão seria investigar tais parâmetros a longo prazo realizando a cocultura após as mo-DC já estarem diferenciadas ou maturadas para verificar alguma evidência de reversão da diferenciação e ou maturação das mo-DC.

Zhang et al. (2004) cocultivaram CTM isoladas de medula óssea (CTMO) com moDC CD14+. As CTMO inibiram a diferenciação de monócitos em iDC, evidenciado pela diminuição da expressão de CD1a. Da mesma forma, como encontrado no presente trabalho, verificou-se que a molécula BDCA1 (CD1c) também foi diminuída. Em relação às $\mathrm{mDC}$, Zhang et al. verificou a diminuição das moléculas coestimuladoras de superfícies CD40, CD80 e CD86. Adicionalmente os autores verificaram o efeito do sobrenadante das CTMO sobre as iDC e mDC, que promoveu apenas a diminuição da expressão de CD83 em mDC.

Choi et al. (2012) realizaram os mesmo experimento que o presente trabalho, porém, em CTMO murinas. Apesar do uso de células murinas, os resultados desses autores, utilizando CTM não irradiadas, suportam os resultados apresentados aqui. Essa decisão foi tomada para excluirmos qualquer possibilidade de modificação genômica no metabolismo das CTIPD que poderia ser causada pela irradiação gama. Choi et al.(2012) cocultivaram CTMO e DC onde o efeito imunomodulador foi bem evidente. Os autores denominaram as DC presentes no conjunto CTMO:DC como um distinto subtipo celular caracterizado por ser positivo para CD11b e negativas para CD1a, CD80, CD83, CD86 e CD40.

Outro estudo verificou o potencial da CTM sobre a diferenciação e maturação das células-tronco hematopoiéticas $(\mathrm{CTH})$ para DC. O cocultivo entre estas células mostrou que as CTM inibiram a diferenciação das CTH, constatado pela verificação de marcadores de estágio progenitor [CD117 (c-kit), CD123 (receptor IL3), e CD116 (receptor de GM-CSF)] e de diferenciação (CD4, CD14 e E-cadherin) os quais permaneceram inalterados ou pouco alterados, menos para os marcadores CD11c e CD1a. Durante a diferenciação CD86 e HLADR foram levemente diminuídos. No entanto, ao longo do tempo células semelhantes as DC tenderam à diferenciação. $\mathrm{O}$ cálculo do número absoluto de progênies $\mathrm{DC}$ de diferentes culturas derivadas de CTH demonstrou que CTM inibiram a geração de muitos subtipos de DC mielóides, incluindo monócitos CD14+, CD4+ DC (provável precursor de pan-DC), células de Langerhans CD11c+Ecad+ (LC), e DC mielóides CD11c+. Foi verificado também que a cocultura de células semelhantes às DC, CTM e células T naïve, inibiu a atividade das DC ativarem essas células T naïve. Como a cocultura entre CTM e CTH mostrou efeito 
imunomodulador, tanto cultura com contato célula-célula ou utilizando transwell, especulouse que fatores e citocinas eram as responsáveis pela imunomodulação. A cocultura mostrou que houve significante supressão TNF- $\alpha$ e TGF- $\beta 1$ e aumento da expressão de IL1 $\beta$ e IL6. Interessantemente, os níveis de IL1 $\beta$ e IL6 foram maiores quando houve contato célula-célula (Lai et al., 2010).

As DC têm duas funções importantes dependendo de seu estado se imatura (iDC) ou matura (mDC). iDC ou DC em repouso são pobres em estimular proliferação de Lin T e tem sido mostrado induzirem o estado de tolerância tanto in vitro quanto in vivo. (Aggarwall et al., 2005, Rissoan et al., 1999, Zhang et al., 2004). Quando estimuladas por LPS, DNA contendo CpG não metilado, IFN- $\gamma$ ou ligante de CD40, iDC mudam de células capturadoras de antígenos para mDC, apresentadoras de antígenos (APC) e estimuladoras de Lin T (Zhang et al., 2004). No entanto, o presente trabalho mostrou que mo-DC cocultivadas com CTIPD reduziram a capacidade estimuladora de proliferação de Lin T. Assim, algumas hipóteses são levantadas. As CTIPD inibiram a diferenciação das mo-DC, a ativação de mDC, as tornaram tolerogênicas, e o papel dos fatores solúveis?

No presente trabalho, tanto as iDC quanto as $\mathrm{mDC}$ induziram a proliferação de Lin T. No entanto, quando essas mo-DC foram cocultivadas com CTIPD e posteriormente transferidas para cultura com Lin $\mathrm{T}$, diminuíram sua função em estimular tanto de Lin $\mathrm{T}$ CD4+ quanto de CD8+. Estes resultados mostraram que a imunomodulação promovidas pelas CTIPD na diferenciação e maturação de mo-DC afetou a funcionalidade das mo-DC como APC na estimulação de Lin T. Zhang et al. (2004) observaram a diminuição da proliferação de Lin T na presença de DC previamente coculltivadas com CTMO. Zhao et al. (2012) cultivaram Lin T CD4+ com iDC, mDC ou CTMO:DC (alogênicas) por 3 dias e, em seguida, foram recultivadas com mDC alogênicas ou PHA. Foi verificado que o contato com CTMO:DC levou Lin T CD4+ a uma baixa resposta ao estímulo de mDC ou PHA. A inibição da estimulação de Lin T CD8+, apresentado neste trabalho, vai de encontro com os resultados encontrados por Rasmusson et al. (2007) onde demonstraram que as CTMO escaparam ao reconhecimento pelos Lin T citotóxicos e células natural killers (NK).

A proliferação de Lin T foi reduzida pelas mDC[CTIPD], assim, a partir desses Lin T CD4+ remanescentes, qual proporção era FoxP3+? English et al. (2009) mostraram aumento da expressão de FoxP3 e aumento da população de Lin T CD4+CD25+FoxP3+ na cocultura entre CTM e Lin T CD4+. A indução de Lin T CD4+CD25+FoxP3+ não foi observada em cocultura entre Lin T CD4+ e CTM utilizando transwell, mas foi induzida em cocultura em transwell com PBMC e CTM, mostrando a importância de fatores solúveis liberados pela 
CTM e da contribuição de outras células do sistema imunológico. Os mesmos resultados foram obtidos por Choi et al. (2012) estudando a cocultura de células de camundongos entre esplenócitos, iDC e CTM, onde foi observada o aumento da função imunomoduladora das iDC em induzir Treg FoxP3+. Zhao et al. (2012) mostraram que a cocultura com DC e CTM geram Lin T CD4+CD25+Foxp3+ a partir de células Treg CD4+CD25-, e propuseram que a combinação CTM:DC pode representar um subconjunto distinto de DC com função reguladora. No presente trabalho nós mostramos que CTIPD também têm a propriedade de imunomodular as mDC em aumentar a proporção de Lin T CD4+Foxp3+, dando às mDC um perfil regulador.

Nós investigamos a população de Lin T CD4+Foxp3+ induzidas pelas mDC[CTIPD] e observamos aumento da proporção de Lin T CD4+FoxP3+IL-10+ em comparação com Lin T CD4+ cocultivados apenas com mDC. Couper et al. (2012) propuseram que essa população é uma fonte de IL-10 com função para controlar uma resposta inflamatória exacerbada. Recentemente, foram obtidos resultados que indicam que Treg produzem IL-10 induzida pelo receptor de IL-10 (IL-10R) em um circuito fechado de realimentação positiva que pode então resultar na diminuição da resposta de células Th17 (Chaudhry et al., 2011). Conforme descrito abaixo, este resultado se encaixa com nosso resultado onde observamos aumento da secreção de IL-10 em cocultura entre Lin T e mDC[CTIPD].

Esta mesma população de Lin T CD4+FoxP3+ induzidas por mDC[CTIPD] levou ao aumento da proporção de Lin T CD4+Foxp3+IFN- $\gamma+$. Oldenhove et al. (2009) observaram que Lin T FoxP3+ apresentaram aumento do marcador intracelular de IFN- $\gamma$ no estudo de Lin $\mathrm{T}$ de camundongos infectados com Toxoplasma gondii. Os autores mostraram, no contexto infeccioso, que Lin T FoxP3+ expressaram T-bet (fator de transcrição que controlam a expressão da citocina marca Th1, IFN- $\gamma$ ) e a produzirem IFN- $\gamma$, deste modo, os autores sugerem que Lin T FoxP3+ adquiriram propriedades de Lin Th1. Recentemente, Ouyang et al. (2012) propuseram que Foxo1 é um fator de transcrição que controla a função das células Treg, e sua exportação para citosol, após ativação do receptor de células T (do inglês, $T$-cell receptor - TCR), leva a produção de IFN- $\gamma$ pelos Lin T CD4+Foxp3+. No entanto, a questão é, por que CTIPD aumenta a proporção de Lin T FoxP3+IFN- $\gamma+$ ? Oldenhove et al. (2009) observaram que a expressão de T-bet não interfere com a capacidade de Lin Treg para suprimir a proliferação de Lin T efetoras e a produção de IFN- $\gamma$ in vitro. Assim, é intrigante, como foi encontrado na cocultura de Lin $\mathrm{T}$ com mDC[CTIPD] a ocorrência concomitantemente do aumento da proporção de Lin T CD4+FoxP3+IFN- $\gamma$ e a redução de 
INF- $\gamma$ no sobrenadante. Pretende-se futuramente investigar se esta população de Lin T CD4+Foxp3+INF- $\gamma+$ gerada pelas mDC[CTIPD] têm atividade funcional de Lin Treg.

Fatores solúveis dirigem a progressão das células imunes para um perfil imunogênico ou tolerogênico, inflamatório ou anti-inflamatório (Aggarwall et al., 2005). Os resultados obtidos sobre a investigação dos fatores IL-2, IL-6, IL-10, TNF- $\alpha$ e IFN- $\gamma$ se tornaram mais interessantes quando as coculturas com mDC são analisadas, cuja presença no sobrenadante foi mais expressiva em comparação as culturas com iDC. Os fatores pró-inflamatórios IL-2, TNF- $\alpha$ e IFN- $\gamma$ tiveram sua secreção diminuídas quando as $\mathrm{mDC}$ foram cocultivadas com CTIPD. A secreção da citocina IL-10, relacionada ao aspecto anti-inflamatório e tolerogênico, estava aumentada na presença das CTIPD. No cocultivo com Lin T, os fatores foram imunomodulados pelas mo-DC previamente cocultivados com CTIPD . Dessa forma, IL-2, TNF- $\alpha$ e IFN- $\gamma$ tiveram a secreção diminuídas na cocultura entre Lin T e mDC[CTIPD]. Já IL-10, na mesma condição de cocultivo, apresentou sua expressão aumentada. Verificou-se que o padrão de secreção e imunomodulação se repetem tanto para as culturas de mDC cocultivadas com CTPID como para a cocultura de Lin $\mathrm{T}$ cocultivados com as mDC imunomoduladas pelas CTIPD.

Os fenômenos observados acima foram presenciados em experimentos utilizando CTMO. O cocultivo com CTMO levaram as DC secretarem não só mais IL-10, como também TGF- $\beta 1$ e a diminuir a secreção de IL-12; sendo este perfil foi realçado na presença de LPS (Zhao et al., 2012). Os mesmo autores cocultivaram Lin T:mDC ou Lin T:PHA com CTMO:DC mostrando que houve uma significante redução na proliferação desses Lin T estimulados e que a concentração da IL-2 e IFN- $\gamma$ no sobrenadante foi fortemente reduzida. Quando o mesmo experimento foi realizado em transwell, ocorreu a redução na proliferação de Lin T estimulados com PHA, no entanto, o efeito foi menor quando comparado com o cultivo onde houve contato celular. Isso mostra que fatores solúveis tem um importante papel na imunomodulação promovida por CTMO:DC e também mostra a importância do contato células-célula para que a imunomodulação seja eficiente. Os autores utilizaram inibidores para avaliar o papel dos fatores investigados acima. Apenas a inibição de TGF- $\beta 1$ conseguiu reverter a capacidade de redução da proliferação de Lin T CD4+ cocultivados com CTMO:DC. Contudo, o contato célula-célula ainda é imprescindível, uma vez que o uso de transwell diminuiu a eficiência da inibição da proliferação de Lin T pelas CTMO:DC.

A secreção da citocina IL-6 nos cultivos com mDC ou mDC:CTIPD não foi alterada. No entanto, no cultivo de iDC, onde não houve secreção de IL-6, quando na presença das CTIPD os níveis foram altos, atingindo o mesmo patarmar dos níveis das culturas com mDC e 
mDC:CTIPD. Este resultado já era esperado uma vez que CTM liberam IL-6 (Aggarwal et al., 2005, Rasmusson et al., 2007). No presente trabalho, quando Lin T foram cocultivados com mDC (que mantiveram contato ou não com CTIPD) a IL-6 apresentou níveis mais elevados em comparação com a cocultura com iDC. CTMO produzem IL-6 constitutivamente, que é aumentada quando estimuladas com LPS (Rasmusson et al., 2007).

A IL-6 é uma citocina inflamatória que participa da principalmente da síntese da fase aguda e estimula a proliferação de Lin B produtores de anticorpos, desenvolvimento de Lin Th17 e é secretada por DC ativadas (Rasmunson et al., 2007, Sakata et al., 2010). No entanto, muitos trabalhos vêm mostrando resultados anti-inflamatórios mesmo na presença de IL-6. Sakata et al. (2010) mostraram que prostaglandina E2 suprime a diferenciação de células T naïve em Th17 pela ação de IL-6 e TGF- $\beta$ e Rasmusson et al. (2007) mostraram que CTMO cocultivadas com células mononucleares de baço promoveram a diminuição da produção de IgG, já o cocultivo realizado com linfócitos B isolados aumentou a produção de IgG. Ainda, foi observado que CTM liberam IL-6 e expressam o receptor para IL-6, respondendo a essa citocina aumentando sua migração em oito vezes em comparação com a migração espontânea (Aggarwal et al., 2005, Tondreau et al., 2009). Os resultados do presente trabalho mostrou aumento dos níveis de IL-6 no cocultivo de mDC[CTIPD]:Lin T, porém o efeito na proliferação de Lin $\mathrm{T}$ foi supressor.

Os testes empregados no presente trabalho não permitiram desvendar processos imunomoduladores que poderiam ocorrer além da diferenciação e maturação das mo-DC e estimulação de Lin T pelas mo-DC. O presente trabalho avaliou apenas as populações de Lin T CD4+ e Lin T CD8+ presentes nas CNA, no entanto, analisando a imunomodulação que refletiu alteração dos níveis de fatores secretados no sobrenadante e com base na literatura, podemos prever indiretamente que as CTIPD atuam de forma imunossupressora no balanço entre Lin T pró- e anti-inflamatórios.

Aggarwal et al. (2005) realizaram um estudo que mostrou de forma ampla o efeito imunomodulador das CTMO perante a diferentes tipos e subtipos celulares do sistema imune e fatores correlatos. As CTMO testadas mostraram efeito imunossupressor reduzindo a secreção de TNF- $\alpha$, no cocultivo com DC do tipo 1, e aumentando os níveis de IL-10, junto à DC do tipo2. Este efeito também foi observado na diminuição da secreção de INF- $\gamma$, no cocultivo com Th1, e com o aumento de IL-4, no cocultivo com TH2. Além desses resultados, verificaram que a cocultura entre CTMO:PBMC promoveu aumento da população de Treg. 
Estes resultados entram inclusive em acordo em experimentos realizados com células murinas. Choi et al. (2012) realizaram cocultura entre CTMO:DC:Lin T CD4+ e mostraram a diminuição da secreção da citocina IFN- $\gamma$, citocina secretada por Th1. O aumento da citocina IL-4, molécula secretada por Th2, foi maior no cocultivo entre os três tipos celulares em comparação a cocultura apenas entre CTMO:Lin T CD4+, mas não em comparação com iDC: Lin T CD4+. Em adição, a expressão das IL-10, outra citocina relacionada à Th2, foi marcantemente aumentada na cocultura entre os três tipos celulares. Estes resultados mostram que as iDC podem induzir efeito imunossupressor mediado pelas CTMO, uma vez que o padrão de secreção da razão Th1/Th2 foi distinto do padrão das coculturas apenas com iDC:Lin T CD4+ ou CTMO:Lin T CD4+ (Choi et al., 2012).

Alguns fatores analisados não forneceram resultados expressivos para o presente trabalho. Os níveis de IL-4 não apresentaram imunomodulação esperada como mostra na literatura - o seu aumento na cocultura com CTM (Aggarwal et al., 2005, Choi et al., 2012). O fato é que IL-4 recombinante humano é utilizado para a diferenciação de mo-DC em iDC, dessa forma, este fator está presente em altos níveis na cocultura com iDC e mDC. No entanto, a cocultura de cinco dias entre mo-DC e Lin T ocorre sem a presença de rhIL-4, uma vez que as mo-DC já estão diferenciadas ou maturadas e já sofreram ou não o cocultivo com as CTIPD. Outro fator que não forneceu nenhum resultado revelador foi a IL-17, já que esta só foi produzida no grupo do controle positivo, onde foi utilizado o PHA como estimulador. No entanto, em um trabalho onde os autores comparam a eficiência entre CTM de polpa de dente permanente (CTPD) e CTMO, foi observado que CTPD são mais imunomoduladores que CTMO e que as CTPD são mais eficientes em inibir a proliferação de Th17(Yamaza et al., 2010).

Outras moléculas estão envolvidas na propriedade imunomoduladora das CTM. A cocultura entre CTMO:DC:esplenócitos mostrou aumento na secreção de TGF- $\beta 1$ comparado com as coculturas apenas de CTMO ou iDC:esplenócitos. O mesmo foi visto com linfócitos T CD4+ isoladas de esplenócitos (Choi et al., 2012). A interleucina IL-2 é importante em promover a estimulação de IFN- $\gamma$ pelas células NK e Lin T (Aggarwal et al., 2005, Oldenhove et al., 2009). As CTMO levaram a diminuição da secreção de IFN- $\gamma$ no cocultivo com NK estimuladas por IL-2 (Aggarwal et al., 2005). Outros fatores secretados em culturas com CTMO, além da IL-6, são IL-8, PGE2, e fator de crescimento endotelial vascular (VEGF; Aggarwal et al., 2005). Apesar de necessário o contato célula-célula para a completa imunomodulação do sistema imune pelas CTM, alguns trabalhos mostraram que algumas moléculas solúveis têm um papel central como imunossupressoras como PGE2, TGF- $\beta 1$ e 
indoleamina 2,3-dioxigenase, onde a adição de inibidores dessas moléculas reverteu o efeito imunossupressor das CTM (Aggarwal et al., 2005, Yagi et al., 2010, Zhao et al., 2012).

A ação direta de contato célula-célula é mais significativa que indiretamente via citocinas, ou que no mínimo é mais completo, pois apenas as citocinas mostraram efeitos parciais ao efeito direto das CTM sobre as DC. Apesar das DC não terem a capacidade de expandir Treg CD4+CD25+Foxp3+, elas foram capazes de gerar Treg CD4+CD25+Foxp3+a partir de células T CD4+CD25+. Tal efeito indutor é promovido pelo contato direto célulacélula uma vez que o uso de transwell aboliu a geração de Treg CD4+CD25+Foxp3+. O uso de anti-IL10 e anti-TGF- $\beta 1$, não alterou a capacidade das CTM:DC gerarem Treg CD4+CD25+Foxp3+. Essas células geradas se mostraram funcionais, uma vez que elas inibiram a proliferação de Lin T CD4+, onde tal efeito foi dose dependente. A utilização de anti-IL10 e anti-TGF- $\beta 1$ não reverteu o efeito proliferativos das Treg CD4+CD25+Foxp3+ sobre Lin T CD4+. No entanto, o uso de transwell provou que o contato célula-célula é necessário para que haja a inibição de Lin TCD4+ pelas Treg CD4+CD25+Foxp3+ geradas por CTM:DC (Zhao et al., 2012).

Diante desse panorama alguns autores propuseram modelos para explicar os mecanismos imunomoduladores das CTM. Argawall et al. (2004) esquematizaram um modelo da interação de CTM com diversas células do sistema imunológico, e sugerem que as CTM inibem ou limitam a resposta inflamatória, ao menos promovendo caminhos de mitigação. Quando CTM estão presentes em um ambiente inflamatório criado artificialmente (in vitro), elas alteram a resposta imune, inibindo a sinalização inflamatórias promovida pelas DC do tipo 1 (diminuindo a secreção de IL-12 e TNF- $\alpha$ ), e promovem sinalização anti-inflamatória de DC do tipo 2 (aumentando a secreção de IL -10). Além disso, quando as Lin T imaturas estão presentes, CTM podem interagir e inibir o desenvolvimento de Th1, a sinalização de NK (pela diminuição da secreção de INF- $\gamma$ ), promover sinalização anti-inflamatória de Th2 e induzir o efeito supressivo de Treg (aumentando a secreção de IL4) . Yagi et al. (2010) propuseram um modelo para interações de citocinas. CTM que expressam MHC-II, funcionam como APC quando cultivadas com baixos níveis de IFN- $\gamma$. Em níveis elevados de IFN- $\gamma$, MHC-II é suprimida e B7-H1 é regulada positivamente. IFN- $\gamma$ e TNF- $\alpha$ individualmente estimulam CTM para regular positivamente PGE2, COX-2 e IDO. Estes mediadores podem inibir a função das células imunitárias, tais como Lin T, células NK e DC.

Assim como afirmado por Zhao et al. (2004), mo-DC imunomoduladas pelas CTM (no caso do presente trabalho, as CTIPD) alogênicas possuem baixa imunogenicidade e forte função imunoreguladora. Futuramente seria interessante investigar o balanço entre Th1 e Th2 
e a imunomodulação de DC do tipo 2 plasmocitóide, uma vez que o presente trabalho mostrou que em cocultura de CTIPD com mo-DC (que possui a população DC do tipo 1 BDCA1+) aumentou a secreção de IL-10, citocina marcantemente secretada por DC do tipo 2, cuja propriedade tanto dessas células quanto da citocina é regular Th2 alterando o balanço Th1/Th2 de pró-inflamatória para anti-inflamatória (Aggarwall et al., 2005, Rissoan et al., 1999). Ainda, não apenas isoladamente, mas a interação CTM:DC forma uma espécie de "subtipo celular" imune capaz de possivelmente trazer homeostasia a um ambiente imunologicamente desbalanceado. Outra população que merece atenção são os Lin T CD4+FoxP3+INF- $\gamma+$, investigando se possuem funcionalidade de Lin Treg, que também trazem homeostase imunológica.

Conclui-se que as CTIPD possui ação imunomoduladora sobre DC derivadas de monócitos. Foi observado que mo-DC tiveram a diminuição de moléculas relacionadas à diferenciação de monócitos para iDC, como a molécula BDCA-1, e o aumento da molécula CD14 relacionada ao estágio precursor mielóide. Essa atenuação na diferenciação parece ter refletido na maturação para $\mathrm{mDC}$, verificado pela diminuição das moléculas de maturação, principalmente CD40. As mo-DC pré-cultivadas com CTIPD tiverem sua função em induzir a proliferação de Lin $\mathrm{T}$ reduzida, além, de favorecer o aumento da proporção de Lin $\mathrm{T}$ CD4+FoxP3+IL-10+ e Lin T CD4+FoxP3+IFN- $\gamma+$. A mensuração dos fatores solúveis dos cocultivos entre mo-DC e CTIPD e entre mo-DC (pré-cultivadas com CTIPD) e Lin T mostrou que houve aumento de fatores anti-inflamatórios e diminuição de fatores próinflamatórios, indicando um balanço em direção um contexto anti-inflamatório imunomodulado pelas CTIPD. Estes resultados fornecem respaldo para futuras investigações do potencial uso de CTIPD em imunoterapia celular voltados para doenças autoimunes, inflamatórias e procedimentos que envolvem enxertos e cicatrização, como também no processo de imunomodulação das DC (como de outras células do sistema imune) para os mesmos fins terapêuticos. 


\section{REFERÊNCIAS*}

Abbas AK, Litchman AH, Pober JS. Imunologia celular e molecular. $6^{\text {a }}$ ed. Rio de Janeiro: Revinter, 2008. 564 p.

Abe K, Yarovinsky FO, Murakami T, Shakhov AN, Tumanov AV, Ito D, Drutskaya LN, Pfeffer K, Kuprash DV, Komschlies KL, Nedospasov SA. Distinct contributions of TNF and LT cytokines to the de-velopment of dendritic cells in vitro and their re-cruitment in vivo. Blood. 2003;101:1477-83.

Abott A. German researchers seek legal backing for stem cell work. Nature 2000;404(6777): 424.

Aggarwal S, Pittenger MF. Human mesenchymal stem cells modulateallogeneic immune cell responses. Blood. 2005;105(4):1815-22.

Angelot F, Seillès E, Biichlé S, Berda Y, Gaugler B, Plumas J, Chaperot L, Dignat-George F, Tiberghien P, Saas P, Garnache-Ottou F. Endothelial cell-derived microparticles induce plasmacytoid dendritic cell maturation: potential implications in inflammatory diseases. Haematologica. 2009;94(11):502-12.

Banchereau J, Steinman RM. Dendritic cells and the control of immunity. Nature. 1998;392:245-52.

Bartholomew A, Sturgeon C, Siatskas M, Ferrer K, McIntosh K, Patil S, Hardy W, Devine S, Ucker D, Deans R, Moseley A, Hoffman R.. Mesenchymal stem cells suppress lymphocyte proliferation in vitro and prolong skin graft survival in vivo. Exp Hematol.2002;30(1):42-8.

Caplan AI. Mesenchymal stem cells. Orthop Res. 1991;9(5):641-50.

Chan JL, Tang KC, Patel AP, Bonilla LM, Pierobon N, Ponzio NM, Rameshwar P. Antigenpresenting property of mesenchymal stem cells occurs during a narrow window at low levels of interferon-gamma. Blood. 2006;107(12):4817-24.

Chapuis F, Rosenzwajg M, Yagello M, Ekman M, Biberfeld P, Gluckman JC.. Differentiation of human dendritic cells from monocytes in vitro. Eur J Immunol. 1997;27:431-41.

Chaudhry A, Samstein RM, Treuting P, Liang Y, Pils MC, Heinrich JM, Jack RS, Wunderlich FT, Brüning JC, Müller W, Rudensky AY. Interleukin-10 signaling in regulatory T cells is required for suppression of Th17 cell-mediated inflammation. Immunity. 2011;34(4):566-78.

Choi YS, Jeong JA, Lim DS. Mesenchymal stem cell-mediated immature dendritic cells induce regulatory $\mathrm{T}$ cell-based immunosuppressive effect. Immunological Investigations. 2012;41:214-29.

Couper KN, Blount DG, Riley EM. IL-10: The Master regulator of immunity to infection. J Immunol. 2008;180:5771-77.

\footnotetext{
* De acordo com:

International Committee of Medical Journal Editors. [Internet]. Uniform requirements for manuscripts submitted to Biomedical Journal: sample references. [updated 2011 Jul 15]. Available from: http://www.icmje.org.
} 
Dzionek A, Fuchs A, Schmidt P, Cremer S, Zysk M, Miltenyi S, Buck DW, Schmitz J. BDCA-2, BDCA-3, and BDCA-4: three markers for distinct subsets of dendritic cells in human peripheral blood. J Immunol. 2000;165:6037-46.

Gerdoni E, Gallo B, Casazza S, Musio S, Bonanni I, Pedemonte E, Mantegazza R, Frassoni F, Mancardi G, Pedotti R, Uccelli A. Mesenchymal stem cells effectively modulate pathogenic immune response in experimental autoimmune encephalomyelitis. Ann Neurol. 2007;61(3):219-27.

Glennie S, Soeiro I, Dyson PJ, Lam EW, Dazzi F. Bone marrow mesenchymal stem cells induce division arrest anergy of activated T cells. Blood. 2005;105(7):2821-7.

Gronthos S, Mankani M, Brahim J, Robey PG, Shi S. Postnatal human dental pulp stem cells (DPSCs) in vitro and in vivo. Proc Natl Acad Sci USA. 2000; 97(25):13625-30.

Iyer SS, Rojas, M. Anti-infl ammatory effects of mesenchymal stem cells: novel concept for future therapies. Expert Opin Biol Ther. 2008;8(5):569-81.

Jewett A, Arasteh A, Tseng HC, Behel A, Arasteh H, Yang W, Cacalano NA, Paranjpe A. Strategies to rescue mesenchymal stem cells (MSCs) and dental pulp stem cells (DPSCs) from NK cell mediated cytotoxicity. PLoS One. 2010;5(3):1-14.

Kerkis I, Kerkis A, Dozortsev D, Stukart-Parsons GC, Gomes Massironi SM, Pereira LV, Caplan AI, Cerruti HF. Isolation and characterization of sub-population of dental pulp stem cells expressing OCT-4 and other key embryonic stem cells markers. Cells Tissues Organs. 2006;184:105-16.

Krampera M, Glennie S, Dyson J, Scott D, Laylor R, Simpson E, Dazzi F. Bone marrow mesenchymal stem cells inhibit the response of naive and memory antigen-specifi c $\mathrm{T}$ cells to their cognate peptide. Blood. 2003;101(9):3722-9.

La Cava A. T-regulatory cells in systemic lupus erythematosus. Lupus. 2008,17:421-5.

Labeur MS, Roters B, Pers B, Mehling A, Luger TA, Schwarz T, Grabbe S. Generation of tumor immunity by bone marrow-derived dendritic cells correlates with dendritic cell maturation stage. J Immunol. 1999;162:168-75.

Lai HY, Yang MJ, Wen KC, Chao KC, Shih CC, Lee OK. Mesenchymal stem cells negatively regulate dendritic lineage commitment of umbilical-cord-blood-derived hematopoietic stem cells: an unappreciated mechanism as immunomodulators. Tissue Engineering: Part A. 2010;16(9):2987-97.

Le Blanc K, Rasmusson I, Götherström C, Seidel C, Sundberg B, Sundin M, Rosendahl K, Tammik C, Ringdén O. Mesenchymal stem cells inhibit the expression of CD25 (interleukin2 receptor) and CD38 on phytohaemagglutinin-activated lymphocytes. Scand J Immunol. 2004;60(3):307-15.

Le Blanc K, Tammik C, Rosendahl K, Zetterberg E, Ringdén O. HLA expression and immunologic properties of differentiated and undifferentiated mesenchymal stem cells. Exp Hematol. 2003;31(10):890-6. 
Le Blanc K, Tammik L, Sundberg B, Haynesworth SE, Ringdén O. Mesenchymal stem cells inhibit and stimulate mixed lymphocyte cultures and mitogenic responses independently of the major histocompatibility complex. Scand J Immunol. 2003;57(1):11-20.

Li YP, Paczesny S, Lauret E, Poirault S, Bordigoni P, Mekhloufi F, Hequet O, Bertrand Y, Ou-Yang JP, Stoltz JF, Miossec P, Eljaafari A. Human mesenchymal stem cells license adult CD34+ hemopoietic progenitor cells to differentiate into regulatory dendritic cells through activation of the Notch pathway. J Immunol. 2008;180(3):1598-608.

Liu YJ, Dendritic cell subsets and lineages, and their functions in innate and adaptive immunity. Cell. 2001;106:259-62.

Maldonado-Lopez R, Moser M. Dendritic cell sub-sets and the regulation of Th1/Th2 responses. Semin Immunol. 2001;13:275-82.

Marchal-Sommé J, Uzunhan Y, Marchand-Adam S, Kambouchner M, Valeyre D, Crestani B, Soler P. Dendritic cells accumulate in human fibrotic interstitial lung disease. Am J Respir Crit Care Med. 2007;176(10):1007-14.

Maus U, Herold S, Muth H, Maus R, Ermert L, Ermert M, Weissmann N, Rosseau S, Seeger W, Grimminger F, Lohmeyer J. Monocytes recruited into the alveolar air space of mice show a monocytic phenotype but upregulateCD14. Am J Physiol Lung Cell Mol Physiol. 2001;280:58-68.

Mei SH, McCarter SD, Deng Y, Parker CH, Liles WC, Stewart DJ. Prevention of LPSinduced acute lung injury in mice by mesenchymal stem cells overexpressing angiopoietin 1 . PLoS Med. 2007;4(9):269.

Miura M, Gronthos S, Zhao M, Lu B, Fisher LW, Robey PG, Shi S. SHED: stem cells from human exfoliated deciduous teeth. Proc Natl Acad Sci USA. 2003;100(10):5807-12

Nimmerjahn F, Ravetch JV. Fcg Receptors: Old friends and new family members. Immunity. 2006;24:19-28.

Oldenhove G, Bouladoux N, Wohlfert EA, Hall JA, Chou D, Dos Santos L, O'Brien S, Blank R, Lamb E, Natarajan S, Kastenmayer R, Hunter C, Grigg ME, Belkaid Y. Decrease of Foxp3+ Treg cell number and acquisition of effector cell phenotype during lethal infection. Immunity. 2009;31(5):772-86.

Ohnishi S, Yanagawa B, Tanaka K, Miyahara Y, Obata H, Kataoka M, Kodama M, IshibashiUeda H, Kangawa K, Kitamura S, Nagaya N. Transplantation of mesenchymal stem cells attenuates myocardial injury and dysfunction in a rat model of acute myocarditis. J Mol Cell Cardiol. 2007;42(1):88-97.

Ortiz LA, Gambelli F, McBride C, Gaupp D, Baddoo M, Kaminski N, Phinney DG. Mesenchymal stem cell engraftment in lung is enhanced in response to bleomycin exposure and ameliorates its fibrotic effects. Proc Natl Acad Sci USA. 2003;100(14):8407-11. 
Oyoshi MK, Barthel R, Tsitsikovet EN. TRAF1 regulates recruitment of lymphocytes and, to a lesser extent, neutrophils, myeloid dendritic cells and monocytes to the lung airways following lipopolysaccharide inhalation. Immunology. 2006;120:303-14.

Oyoshi MK, Bryce P, Goya S, Pichavant M, Umetsu DT, Oettgen HC, Tsitsikov EN. TNF receptor-associated factor 1 expressed in resident lung cells is required for the development of allergic lung inflammation. J Immunol. 2008;180(3):1878-85.

Parekkadan B, van Poll D, Suganuma K, Carter EA, Berthiaume F, Tilles AW, Yarmush ML. Mesenchymal stem cell-derived molecules reverse fulminant hepatic failure. PLoS One. 2007;2(9):941.

Pierdomenico L, Bonsi L, Calvitti M, Rondelli D, Arpinati M, Chirumbolo G, Becchetti E, Marchionni C, Alviano F, Fossati V, Staffolani N, Franchina M, Grossi A, Bagnara GP. Multipotent mesenchymal stem cells with immunosuppressive activity can be easily isolated from dental pulp. Transplantation. 2005;80(6):836-42.

Rasmusson I, Ringden O, Sundberg B, Le Blanc K. Mesenchymal stem cells inhibit the formation of cytotoxic $\mathrm{T}$ lymphocytes, but not activated cytotoxic $\mathrm{T}$ lymphocytes or natural killer cells. Transplantation. 2003;76(8):1208-13.

Rasmusson I, Uhlin M, Le Blanc K, Levitsky V. Mesenchymal stem cells fail to trigger effector functions of cytotoxic T lymphocytes. J Leukoc Biol. 2007;82(4):887-93.

Rasulov MF, Vasilenko VT, Zaidenov VA, Onishchenko NA. Cell transplantation inhibits infl ammatory reaction and stimulates repair processes in burn wound. Bull Exp Biol Med. 2006;142(1):112-5.

Ravetch JV, Bolland S. IgG Fc receptors. Annu Rev Immunol. 2001;19:275-90.

Rescigno M, Winzler C, Delia D, Mutini C, Lutz M, Ricciardi-Castagnoli P. Dendritic cell maturation is required for initiation of the immune response. J Leukoc Biol. 1997;61:415-21.

Ringdén O, Uzunel M, Rasmusson I, Remberger M, Sundberg B, Lönnies H, Marschall HU, Dlugosz A, Szakos A, Hassan Z, Omazic B, Aschan J, Barkholt L, Le Blanc K.Mesenchymal stem cells for treatment of therapy-resistant graft-versus-host disease. Transplantation. 2006;81(10):1390-7.

Rissoan MC, Soumelis V, Kadowaki N, Grouard G, Briere F, Malefyt RW, Liu YJ. Reciprocal control of T helper cell and dendritic cell differentiation. Science. 1999;283:11836.

Ritter U, Meissner A, Ott J, Korner H. Analysis of the maturation process of dendritic cells deficient for TNF and lymphotoxin-alpha reveals an essential role for TNF. J Leukoc Biol. 2003;74:216-22.

Ryan JM, Barry F, Murphy JM, Mahon BP. Interferon-gamma does not break, but promotes the immunosuppressive capacity of adult human mesenchymal stem cells. Clin Exp Immunol. 2007;149(2):353-63. 
Semedo P, Wang PM, Andreucci TH, Cenedeze MA, Teixeira VP, Reis MA, Pacheco-Silva A, Câmara NO. Mesenchymal stem cells ameliorate tissue damages triggered by renal ischemia and reperfusion injury. Transplant Proc. 2007;39(2):421-3.

Steinman RM. DC-SIGN: a guide to some mysteries of dendritic cells. Cell. 2000;100:491-4.

van den Berk LC, Roelofs H, Huijs T, Siebers-Vermeulen KG, Raymakers RA, Kögler G, Figdor CG, Torensma R. Cord blood mesenchymal stem cells propel human dendritic cells to an intermediate maturation state and boost interleukin-12 production by mature dendritic cells. Immunology. 2009;128(4):564-72.

van den Brink MR, Burakoff SJ. Cytolytic path-ways in haematopoietic stem-cell transplantation. Nat Rev Immunol. 2002;2:273-81.

van der Valk J, Brunner D, De Smet K, Fex Svenningsen A, Honegger P, Knudsen LE, Lindl T, Noraberg J, Price A, Scarino ML, Gstraunthaler G. Optimization of chemically defined cell culture media--replacing fetal bovine serum in mammalian in vitro methods. Toxicol in Vitro. 2010;24(4):1053-63.

Vermaelen K, Pauwels R. Accurate and simple discrimination of mouse pulmonary dendritic cell and macrophage populations by flow cytometry: methodology and new insights. Cytometry A. 2004;61(2):170-7.

von Wulffen W, Steinmueller M, Herold S, Marsh LM, Bulau P, Seeger W, Welte T, Lohmeyer J, Maus UA. Lung dendritic cells elicited by Fms-like tyrosin 3-kinase ligand amplify the lung inflammatory response to lipopolysaccharide. Am J Respir Crit Care Med. 2007; 176:892-901.

Yagi H, Soto-Gutierrez A, Parekkadan B, Kitagawa Y, Tompkins RG, Kobayashi N, Yarmush ML. Mesenchymal Stem Cells: Mechanisms of immunomodulation and homing. Cell Transplant. 2010;19(6):667-79.

Yamamura T. Differentiation of pulpal cells and inductive influences of various matrices with reference to pulpal wound healing. J Dent Res. 1985;64:530-40.

Yamaza T, Kentaro A, Chen C, Liu Y, Shi Y, Gronthos S, Wang S, Shi S. Immunomodulatory properties of stem cells from human exfoliated deciduous teeth. Stem Cell Research \& Therapy. 2010;1(5):1-10.

Yan X, Liu Y, Han Q, Jia M, Liao L, Qi M, Zhao RC. Injured microenvironment directly guides the differentiation of engrafted Flk-1(+) mesenchymal stem cell in lung. Exp Hematol. 2007;35(9):1466-75.

Zhang R, Becnel L, Li M. C-reactive protein impairs human CD14+ monocyte-derived dendritic cell differentiation, maturation and function. Eur. J. Immunol. 2006.36:2993-3006.

Zhang W, Ge W, Li C, You S, Liao L, Han Q, Deng W, Zhao RC. Effects of mesenchymal stem cells on differentiation, maturation, and function of human monocyte-derived dendritic cells. Stem Cells Dev. 2004;13:263-71. 
Zhou LJ, Tedder TF. CD14+ blood monocytes can differentiate into functionally mature CD83+ dendritic cells. Proc Natl Acad Sci USA. 1996;93:2588-92. 